\title{
Haemangioma of the Testis: A Review and Update of the
}

\section{Literature}

\section{Anthony Kodzo-Grey Venyo}

North Manchester General Hospital, Department of Urology Manchester, M8 5RB, United Kingdom.

\section{ABSTRACT}

Less than 60 cases of haemangiomas of the testis (HOTs) have been reported sporadically in different parts of the world in diverse age groups including in children and adults even though it has been more commonly reported in individuals who are younger than 20 years. HOTs may present with lump/mass in testis/scrotum, scrotal enlargement with or without associated pain/discomfort. The results of serum germ cell tumour marker levels tend to be normal always. The clinical examination does reveal a discrete lump/mass in the testis which may or may not be tender. Radiology imaging does illustrate a discrete mass which usually tends to be well-demarcated but at times the lesion could be abutting the tunica albuginea testis. Doppler scan would tend to show increased vascularity and blood flow within the lesion which may also contain calcifications and at times radiology imaging could illustrate some degree of mild contrast enhancement and these features at times may suggest the possibility of benign disease but malignancy cannot be excluded. An incidental lesion of HOT was identified incidentally in radiology imaging in the absence of a palpable mass/lump. The ideal treatment for HOT is testis-sparing partial orchidectomy which has been undertaken in about a third of cases of HOT reported and radical orchidectomy has been undertaken in two-thirds of cases of HOT under a provisional diagnosis of malignant testicular tumour and the final diagnosis has been based upon the post-operative pathology reports. Diagnosis of HOT tends to be based upon the histopathology examination findings of small tubules with red blood cells that are lined by mesothelial like cells that have uniform vesicular nuclei but they can have focally infiltrative growth pattern with entrapment of seminiferous tubules. Immunohistochemistry staining studies of HOTs do show positive staining for Factor VIII, CD31, CD34, and FLI1 but negative staining for Pancytokeratin AE1/AE3, Keratin 8 / 18, EMA, placental herpesvirus 8 , human chorionic gonadotrophin, c-kit, and p53. No recurrence has been reported following either testis-sparing partial orchidectomy after frozen section pathology examination or after radical orchidectomy. If urologist and radiologists have a high index of suspicion for the disease, and intraoperative frozen section excision biopsies are undertaken in all cases of testicular tumours in all age groups with the knowledge of normal levels of germ cell tumour markers then testis-preserving surgery can be undertaken and unnecessary radical orchidectomy can be avoided.

Keywords: Haemangioma; testis; Lactate Dehydrogenase; Ultrasound Scan, Hypoechoic; wellDemarcated; Partial orchidectomy; Radical Orchidectomy; Red blood cells.

Crossref Doi: https://doi.org/10.36437/irmhs.2019.2.6.Z

\section{Introduction}

If a malignant tumour of the testis is suspected, then the standard course of action to be taken does involve a trans-inguinal surgical exploration of the testicular lesion by isolating the testis

together with the tunica from the scrotum and cutting off the spermatic cord at the level of the internal ring. [1] It has also been iterated that if there are doubts as to the tumour being a 
malignant tumour, an intra-operative histopathology examination of a sample obtained from the lesion, or even better, of the entire lesion removed together with a margin of healthy parenchyma of the testis could be performed. [2] [3] It has been iterated that the guidelines of the European Association of Urology do not recommend the undertaking of testis-sparing resection if the other testis is normal, with the exception of special circumstances. Partial resection of the testis (partial orchidectomy) whilst ensuring oncological clearance of tumour could be performed if the volume of the tumoral lesion is smaller than $30 \%$ of the volume of the testis, metachronous or synchronous lesions do occur within the contralateral testis, the testis that is being operated upon is the only testis the individual has and the individual's pre-operative level of serum testosterone is within normal range. Nevertheless, it has been advised that clinicians should be prepared to encounter the coexistence of testicular intraepithelial neoplasia (TIN) in as many as $82 \%$ of their patients. [3] It has been documented that based upon ultrasound scan findings malignant tumours of the testes usually take the form of focal, hypoechogenic lesions, even though they could be typified by a significant diversity in their ultrasound scan features. With regard to malignant lesions of the testis a significant part of non-infiltrated parenchyma of the testis tends to have a preserved echogenicity and structure. With regard to inflammation of the testis or posttraumatic conditions of the testis, the normal structure as well as the echogenicity of the testis could sometimes be barely visualised. In the scenario in which there is limited inflammation or focal haematoma, within the acute phase the remaining part of the testis tends usually to be associated with signs of oedema. [1] Malignant tumoral lesions of the testis could obscure the contours of the testes, where as benign lesions of the testes could cause enlargement of the testes, even though with the absence of irregularities within the outer contours of the testes [1]. It has been stated that the accompanying inflammation reaction and signs of oedema of the epididymis usually do indicate an inflammatory origin of lesions of the testes [1] [4] [5]. To the knowledge of the author less than 60 cases of haemangioma of the testes have been reported and majority of them have been treated by means of radical orchidectomy under a presumed provisional diagnosis of malignant testicular tumours only to appreciate subsequently that the lesions were benign haemangiomas which could have been treated by means of testis-sparing partial orchidectomy with complete excision of the haemangioma from the hind-site. On the other hand in some situations when frozen section pathology examination of the testicular lesions was undertaken and a definite diagnosis of haemangioma of the testis was undertaken, testissparing partial orchidectomy was undertaken successfully. Some of the questions that could be discussed among urologists include: (a) Are there ways by which a urologists would confidently diagnose haemangioma of the testis preoperatively in order to avoid undertaking radical orchidectomy? (b) Would radiology imaging alone be enough for the establishment of the diagnosis of haemangioma of the testis? (c) Should fine needle aspiration biopsy be undertaken when there is suspicion of a haemangioma so that if the diagnosis of haemangioma of testis is confirmed then testis-sparring surgery can be performed? (d) If there is a testicular mass associated with normal levels of serum beta human chorionic gonadotrophin, alpha fetoprotein and lactate dehydrogenase whether all patients should routinely undergo trans inguinal exploration of the testicular mass and complete excision of the testicular lesion before deciding whether to undergo radical orchidectomy or not. (e) If fine 
needle aspiration biopsy is undertaken for a haemangioma of the testis would it lead to excessive intra-scrotal bleeding? (f) In case the testicular lesion contains a malignant tumour would the fine needle aspiration biopsy lead to seeding of tumour cells along the intra-scrotal biopsy tract. The ensuing review and update of the literature article on haemangioma of the testis is divided into two parts (A) Overview and (B) Miscellaneous narrations and discussions from case reports, case series and studies related to haemangioma of the testis.

\section{Aim}

To review and update the literature on haemangioma of the testis.

\section{Method}

Internet data bases were searched including: Google, Google Scholar, Yahoo, and PUBMED. The search words that were used included haemangioma of testis, testicular haemangioma, hemangioma of testis, and testicular hemangioma. Twenty five references were identified which were used to write the review and update article which has been divided into two parts (A) Overview and (B) Miscellaneous narrations and discussions from some case reports, case series, and studies related to haemangioma of the testis.

\section{Results}

\section{(A)Overview}

\section{Definition and General Comments}

- Haemangioma of the testis is a terminology that is utilized for an uncommon, benign neoplasm, which has sporadically been reported within the testis in males whose ages had ranged between 2 months and 77 years [6]; however, haemangioma of the testis can theoretically be found in males of all age groups.

- Because haemangioma of the testis is a benign lesion, it is important to accurately establish its diagnosis in order not to misdiagnose it for a malignant tumour of the testis.

\section{Terminology}

- There are sub-types of haemangioma of the testis including [6] [7]:

- Anastomosing haemangioma

- Capillary haemangioma.

- Cavernous haemangioma.

○ Epithelioid haemangioma.

\section{Presentation}

Some of the presentations of haemangioma of the testis include:

- Lump / Mass in the testis - This may be asymptomatic or at times it could be associated with discomfort or pain.

- An intra-scrotal mass / lump - This may be asymptomatic or associated with discomfort or pain.

- An enlarging or full hemi-scrotum

- Incidental - One case of haemangioma of the testis was diagnosed incidentally in the absence of a palpable testicular lump/mass based upon the results of radiology imaging of the scrotal contents.

\section{Clinical examination features}

Laboratory investigations Urine

- Urinalysis, urine microscopy, culture and sensitivity are general tests that are undertaken as part of the initial assessment of patients who have haemangioma of the testis and generally the results would tend to be normal but if there is any evidence of urinary tract infection, it would be treated appropriately based upon the antibiotic sensitivity pattern of the cultured organism to improve upon the general condition of the individual patient. 


\section{Haematology blood tests}

Full blood count, erythrocyte sedimentation rate (ESR), and coagulation screen are general tests that tend to be undertaken in the general assessment of patients who have haemangioma of the testis but the results would tend to be normal; nevertheless, if there is any abnormality detected it would be investigated accordingly and treated to improve upon the general condition of the individual.

\section{Biochemistry blood tests}

- Serum urea, creatinine, electrolytes, blood glucose, and liver function tests are general tests that tend to be undertaken in the general assessment of patients who have haemangioma of the testis but the results would tend to be normal; nevertheless, if there is any abnormality detected it would be investigated accordingly and treated to improve upon the general condition of the individual.

- Serum Beta Human Chorionic Gonadotrophin (ß-HCG), alpha fetoprotein (AFP), and lactate dehydrogenase (LDH) tests are routine tests that are undertaken in the assessment of patients who have haemangioma of the testis and the results would tend to be normal in all individuals who have haemangioma of the testis only and no germ cell tumour of the testis.

\section{Radiology investigations Ultrasound scan}

- It has been documented that ultrasound radiology imaging of haemangioma does show a homogeneous hypo-echoic mass which tends to be hyper-vascular upon Doppler ultrasound scan studies [6] [8].

- It has been iterated that Doppler ultrasound scan tends to be useful with regard to the diagnosis of haemangiomas of the testis in that it does demonstrate the nature of the mass as well as it does differentiate it from other testicular neoplasms [9].

- It has been iterated that haemangiomas upon sonography scans do vary from hypo-echoic to hyper-echoic or they could be heterogeneous [10].

- Various sizes of calcification tend to be commonly found in haemangioma of the testis but this would not be diagnostic of haemangioma and confirmation of the diagnosis tends to be dependent upon the histopathology and immunohistochemistry study features of the testicular lesion.

- If the serum germ cell tumour marker levels are normal and the ultrasound scan features suggest possibility of a benign lesion of haemangioma then the opportunity of frozen section examination of the testicular lesion should be undertaken to ensure there is avoidance of unnecessary radical orchidectomy.

- In centres where intra-operative ultrasound scan services are available intra-operative ultrasound scan of the testis can be undertaken to guide the surgeon to completely excise all abnormal looking areas of the testis in order to avoid leaving behind any residual haemangioma in the testis.

- Colour Doppler ultrasound scan may demonstrate a dense network of blood vessels as well as increased blood flow within the haemangioma of testis lesion.

\section{Computed tomography (CT) scan}

- CT scan of thorax, abdomen, and pelvis (CT TAP) tends to be done for full staging of a testicular lesion that is provisionally diagnosed as malignant testicular tumour and this CT scan in cases of haemangioma of the testis which has been provisionally 
wrongly diagnosed as a malignant tumour would show no evidence of metastasis or enlarged lymph nodes.

- If a CT scan of the scrotal contents is undertaken as part of investigation of a haemangioma of the testis, it would define the lesion with regard to its site, size, consistency, relation to the tunica albuginea, epididymis and spermatic cord as well as whether the lesion is contrastenhancing or not and whether there are calcifications within the mass but the findings would not be specific. The testicular lesion in haemangioma of the testis could have slight degree of contrastenhancement which could also be found in testicular malignant tumours therefore tissue diagnosis would be required.

\section{Magnetic Resonance Imaging (MRI) Scan}

- MRI scan of thorax, abdomen, and pelvis (MRI TAP) tends to be done for full staging of a testicular lesion that is provisionally diagnosed as malignant testicular tumour and this MRI scan in cases of haemangioma of the testis which has been provisionally wrongly diagnosed as a malignant tumour would show no evidence of metastasis or enlarged lymph nodes.

- If an MRI scan of the scrotal contents is undertaken as part of investigation of a haemangioma of the testis, it would define the lesion with regard to its site, size, consistency, relation to the tunica albuginea, epididymis and spermatic cord as well as whether the lesion is contrastenhancing or not and whether there are calcifications within the mass but the findings would not be specific. The testicular lesion in haemangioma of the testis could have slight degree of contrast- enhancement which could also be found in testicular malignant tumours therefore tissue diagnosis would be required.

- It has been iterated that reports of the utilization of MRI scanning with regard to the diagnosis of capillary haemangiomas of the testes are not common and that in the available descriptions T1- and T2 weighted imaging and the utilization and the utilization of contrast-agent did not allow for the determination whether the testicular lesions were definitely benign or malignant [1] [11] [12]. For this reason all well-demarcated lesions of the testis that may have some degree of contrastenhancement and increased blood flow associated with normal serum levels of beta human chorionic gonadotrophin, alpha fetoprotein, and lactate dehydrogenase should be subjected to frozen section intra-operative pathology examination in order to decide whether testis-sparing orchidectomy or radical orchidectomy should be undertaken. Because of the possibility of seeding of malignant tumour cells or excessive bleeding from a haemangioma, if the MRI scan features suggest the possibility of a benign testicular lesion intra-operative frozen section examination should be undertaken to decide on radical orchidectomy or testis-sparing partial orchidectomy.

\section{Treatment}

- It has been documented that the treatment for haemangioma of the testis, generally has involved the undertaking of orchidectomy in view of the inability by clinicians to exclude a malignant neoplasm of the testis [6] 
- It has been advised that the preferable treatment of haemangioma of the testis should be testicular sparing surgery if it is feasible to undertake such a procedure. [6] [13]

\section{Macroscopic examination features}

- It has been iterated that gross examination of a specimen of haemangioma of the testis does show the ensuing features [6].

- A well circumscribed lesion of the testis.

$\circ$ A reddish brown lesion of the testis.

- A haemorrhagic mass within the testis.

\section{Microscopy pathology examination features}

- The histopathology examination features of haemangioma of the testis have been summated as follows [6]:

○ Microscopy examination of specimens of haemangioma of the testis do tend to show small tubules and some of the tubules tend to contain some red blood cells; the tubules also tend to be lined by mesothelial cells that contain uniform, vesicular nuclei [6].

- The microscopy examination of haemangioma of the testis can show a testicular lesion that has a focally infiltrative growth pattern with the entrapment of seminiferous tubules [6].

\section{Immunohistochemistry staining}

Positive immunohistochemistry staining [6]:

- It has been stated that immunohistochemistry studies of specimens of haemangiomas of the testis do show positive staining for the ensuing markers [6] :

$\begin{array}{ll}\circ & \text { Factor VIII + } \\ \circ & \text { CD31 }+ \\ \circ & \text { CD34 + } \\ \circ & \text { FLI1+ }\end{array}$

Negative immunohistochemistry staining

- It has been stated that immunohistochemistry studies of specimens of haemangiomas of the testis does show negative staining for the ensuing markers [6]:

○ Pancytokeratin AE1/AE3,

- Keratin 8/18,

- Epithelial Membrane Antigen (EMA),

○ Placental alkaline phosphatase,

o Human Herpes Virus 8,

- Human Chorionic Gonadotrophin,

○ C-kit,

○ Melan, and

○ P53.

\section{Differential diagnoses}

- Some of the documented differential diagnoses of haemangioma of the testis include [6]:
- Adenomatoid tumour of the testis.
- Angiosarcoma of the testis.
- Germ cell tumour of the testis.

\section{Outcome}

- The outcome of patients who undergo treatment for haemangioma of the testis has continued to be good with no subsequent recurrence reported.

- Radical orchidectomy has been undertaken as treatment for majority of individuals who have haemangioma of the 
testis under a provisional diagnosis of a possible malignant testicular tumour only to subsequently realise that the testicular lesion was a benign haemangioma and if the diagnosis was known, a testis-sparing partial orchidectomy would have been undertaken and still there would be no recurrence of the haemangioma after complete excision of the haemangioma through a partial orchidectomy.

- For those who had undergone partial orchidectomy to completely excise their haemangiomas of the testis following frozen section pathology examination of the testicular lesion the prognosis has been good with no subsequent recurrence reported.

(B) Miscellaneous narrations and discussions form some case reports, case series, and studies related to haemangioma of the testis.

Montgomery and Epstein [7] described 6 cases of a poorly recognized vascular tumour which could mimic angiosarcoma. They prospectively collected between 1999 and 2008 cases of an uncommon vascular tumour with a proclivity for the genitourinary tract. Montgomery and Epstein [7] summarized their findings as follows:

- There were 6 tumours that had been obtained from 4 men that amounted to $66 \%$ of the patients and 2 women that amounted to $33 \%$ of the cases whose ages had ranged between 49 years and 75 years and with a mean age of 59.5 years that had involved the kidney and hilum of the kidney in 4 patients that amounted to $66 \%$ of the patients, and testis in 2 patients that amounted to $33 \%$ of the patients.

- $\quad$ The tumours had measured between 1.3 $\mathrm{cm}$ and $1.7 \mathrm{~cm}$ with a median measurement of $1.6 \mathrm{~cm}$ and they were observed to be grossly well-marginated and they had a haemorrhagic mahogany spongy features upon gross examination.

- Microscopy histopathology examination of the lesion at low-power did show that the lesions had a loosely lobulated architecture and they were associated with a medium calibre-vessel in 5 out of the 6 patients that amounted to $83 \%$ of the patients.

- Three out of the four (75\%) renal tumours did show minor extensions into the adjacent adipose tissue.

- Upon microscopy examination of the tumours at higher magnification, the tumours were demonstrated to consist of anastomosing sinusoidal capillary-sized vessels that had scattered hobnail endothelial cells within a framework of non-endothelial supporting structures. There was a minimal inflammatory backdrop which had consisted of lymphocytes but not plasma cells or acute inflammation. Mitoses were absent in 5 out of the 6 cases that amounted to $83 \%$ of cases and mitosis was rare in 1 case $(17 \%)$ within the supporting cells. There was cytologic atypia in 1 case (17\%) but there was no evidence of multi-layering of endothelial cells in any of the 6 lesions. There were typical vascular thrombi in 5 out of the 6 lesions that amounted to $83 \%$, and the lesions did have zones of central sclerosis with focal necrosis in 5 out of the 6 cases that amounted to $83 \%$ of cases. Two of the lesions that amounted to 33\% of the lesions did feature prominent extramedullary haematopoiesis and 2 of the lesions (33\%) did contain hyaline globules reminiscent of those that are visualised in Kaposi's sarcoma.

- Immunohistochemistry studies results were available on some of the cases and it 
was documented that the lesions had stained positively with CD34, CD31, and FVIII but they stained negatively for herpes virus type 8, keratin AE1/AE3, epithelial membrane antigen (EMA), HMB45, placental alkaline phosphatase, and for human chorionic gonadotrophin.

- With regard to 5 out of the 6 cases $(83 \%)$, the possibility of angiosarcoma had been raised based upon the anastomosing pattern of the of the lesion.

- One patient was lost to follow-up but on the follow-up of 5 patients that had ranged between 8 months and 36 months with a median follow-up of 12 months and a mean follow-up of 15 months there were no recurrences.

\section{Montgomery and Epstein [7] concluded that:}

- Anastomosing haemangioma of the genitourinary tract is an uncommon neoplasm which does exhibit some overlapping characteristics of both sinusoidal haemangioma and hobnail haemangioma of soft tissue and skin.

- Nevertheless, it is their opinion that haemangioma is a unique neoplasm that has proclivity for the kidney.

- The anastomosing appearance of haemangioma can lead to concern for angiosarcoma; however, despite the small numbers of haemangiomas and limited follow-up with regard to their series, evidence to date does support the benign nature of the lesion.

Kryvenko and Epstein [8], in 2013, stated that haemangioma of the testis is a very uncommon neoplasm with only 25 cases of the disease reported in the English literature. Kryvenko and Epstein [8] reported 8 cases of haemangioma of the testis which they had encountered within their institution between 1992 and 2012. They summarized their findings as follows:

- Out of the 7 consult cases, 4 were malignant, 1 a Leydig cell tumour, and 2 had been recognized as haemangiomas.

- The ages of the patients had ranged between 9 years and 54 years and the mean age of the patients was 32 years, and the median age of the patients was 30 years.

- $\quad$ Seven of the patients had manifested with self-detected palpable lumps, and 2 of the patients had reported having pain.

- Six of the haemangiomas did involve the right testis, and 2 of the haemangiomas involved the left testis.

- Ultrasound scanning had identified hypervascularity with regard to 3 cases.

- History of pelvic radiotherapy, chemotherapy, as well as remote scrotal trauma was present with regard to 3 cases.

- The results of Pre-operative serum tumour markers were negative in 2 out of 2 cases.

- The size of the tumour had varied between $0.5 \mathrm{~cm}$ to $3 \mathrm{~cm}$ and the average size was $1.7 \mathrm{~cm}$ and the median size was $1.8 \mathrm{~cm}$.

- Macroscopic examination of the tumours had shown that six cases were infiltrative within the testis and entrapped benign seminiferous tubules, and 3 of the tumours had invaded the tunica albuginea.

- Microscopy examination of the specimens did show that 3 of the haemangiomas were epithelioid, 2 were anastomosing, 1 was cellular capillary, 1 was capillary, and 1 was cavernous. Mitoses were sparse in all of the cases with the exception of 1 case, which had reached 5 mitoses per 10 high-power fields. With regard to 6 cases, 
seminiferous tubules that were adjoining the haemangioma were atrophic without spermatogenesis.

- Immunohistochemistry staining studies were undertaken in 6 cases, and the tumoral lesions had exhibited positive staining with CD31, CD34, FVIII-related protein, and FLI-1; nevertheless, the lesions exhibited negative staining for pancytokeratin AE1/3, epithelial membrane antigen (EMA), keratin 8/18, placental alkaline phosphatase, human herpes virus 8, human chorionic gonadotrophin, C-kit, melan-A, and p53.

- With regard to cases that were associated with follow-up, with a follow-up that had ranged between 1 month and 72 months, a mean follow-up of 21 months, and a median follow-up of 12 months, there were no recurrences in 7 patients.

\section{Kryvenko and Epstein [8] concluded that:}

- Haemangioma of the testis is an uncommon tumoral lesion with different morphologies having in common an infiltrative growth pattern with entrapment of seminiferous tubules, which should not be considered as a feature of malignancy.

- Clinical and radiology imaging findings could pre-operatively suggest a vascular tumour.

Zaidi et al. [12] reported a 23-year-old man who had presented with a 2-months history of right testicular discomfort. He did not have any history of accident or trauma. His clinical examination revealed a palpable, tender, right testicular mass. He had magnetic resonance imaging of the mass which showed an exophytic lobulated mass lesion that measured $1.6 \mathrm{~cm} \times 1.5 \mathrm{~cm}$ which had arisen from the lower pole of the right testis and Doppler ultrasound scan showed a high vascular flow (see figure1). The remaining right testis and left testis were normal on both scans. The results of his serum tumour markers Beta-Human Chorionic Gonadotrophin, alpha fetoprotein, and lactate dehydrogenase were normal. Based upon the clinical examination and radiology imaging findings a diagnosis of probable malignant tumour of the testis was made and he underwent right radical orchidectomy. Macroscopic examination of the orchidectomy specimen revealed $1.5 \mathrm{~cm}$ circumscribed lobulated grey tan mass which was attached to the lower pole of the testis and which had not involved the tunica vaginalis, tunica albuginea, or epididymis. Microscopy examination of the specimen showed that the tumour had consisted of a proliferation of capillary sized vascular spaces which were lined by flat endothelial cells that contained red blood cells (see figure 2). The encompassing seminiferous tubules were found to be normal. Immunohistochemistry staining studies showed that the cells of the tumoral lesion had exhibited positive staining for CD34 and factor VIII related antigen which had highlighted the endothelial cells that were lining the vascular spaces (see figure 3) that confirmed the vascular nature of the tumour. Immunohistochemistry staining for alpha fetoprotein, inhibin, and CAM5.2 were negative. Based upon the histopathology examination features and the immunohistochemistry staining characteristics of the tumour a diagnosis of capillary haemangioma of the testis was made. At his 7-month follow-up, he was well with no evidence of recurrence.

\section{Zaidi et al. [12] stated the following:}

- Haemangiomas of the soft tissue are the commonest benign tumours of vascular origin. Nevertheless, capillary haemangiomas of the testis are quite rare with only about 22 cases reported in the English literature [14]. 
- Four histological sub-types of benign vascular tumours of the testis had been reported including: [2]

- Cavernous haemangiomas.

- Capillary haemangiomas.

- Histiocytoid haemangiomas.

○ Papillary endothelial hyperplasia.

- Their case was a capillary haemangioma.

- Patients who have haemangioma of the testis tend to manifest with enlargement of the testis with or without tenderness. [15]

- The reported ages of patients who had haemangioma of the testis had ranged between less than one year and older than 70 years [16].

- In patients who have haemangioma of the testis, the levels of serum tumour markers Beta Human Chorionic Gonadotrophin, alpha fetoprotein and lactate dehydrogenase tend to be within normal range [14] [17].

- The clinical appearance and diagnostic examination findings are usually insufficient for the establishment of a definitive diagnosis of haemangioma of the testis and the diagnosis of haemangioma of the testis would require a histopathology examination. Nevertheless, if the surgeons as well as the pathologists are aware haemangioma of the testis, especially when the serum tumour marker levels are within normal range, then conservative management by means of enucleation of tumour with preservation of the testis would be possible if intra-operative frozen section examination could be undertaken.

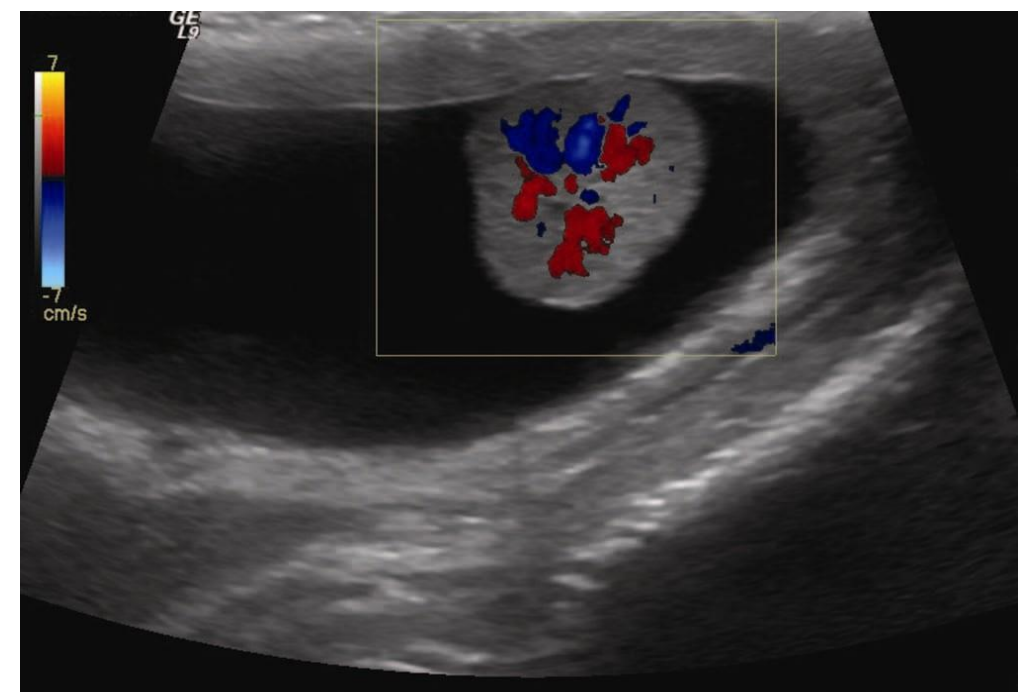

Figure 1: Ultrasonographic findings: Ultrasonography revealed a well defined mass with homogenous echogenicity measuring $1.5 \mathrm{~cm}$ x $1.6 \mathrm{~cm}$, demonstrating high vascular flow on Doppler Ultrasound. Reproduced from: [12] Zaidi S N, Fathaddin A A. Testicular capillary hemangioma - A case report of a rare tumor. Indian Journal of Pathology \&amp; Microbiology; 2012; 55(2): 557 - 559 http://www.ijpmonline.org/article.asp?issn=03774929; year $=2012$; volume $=55 ;$ issue $=4 ;$ spage $=557$; epage $=559$; aulast $=$ Zaidi Accessed 2019 Dec 06 


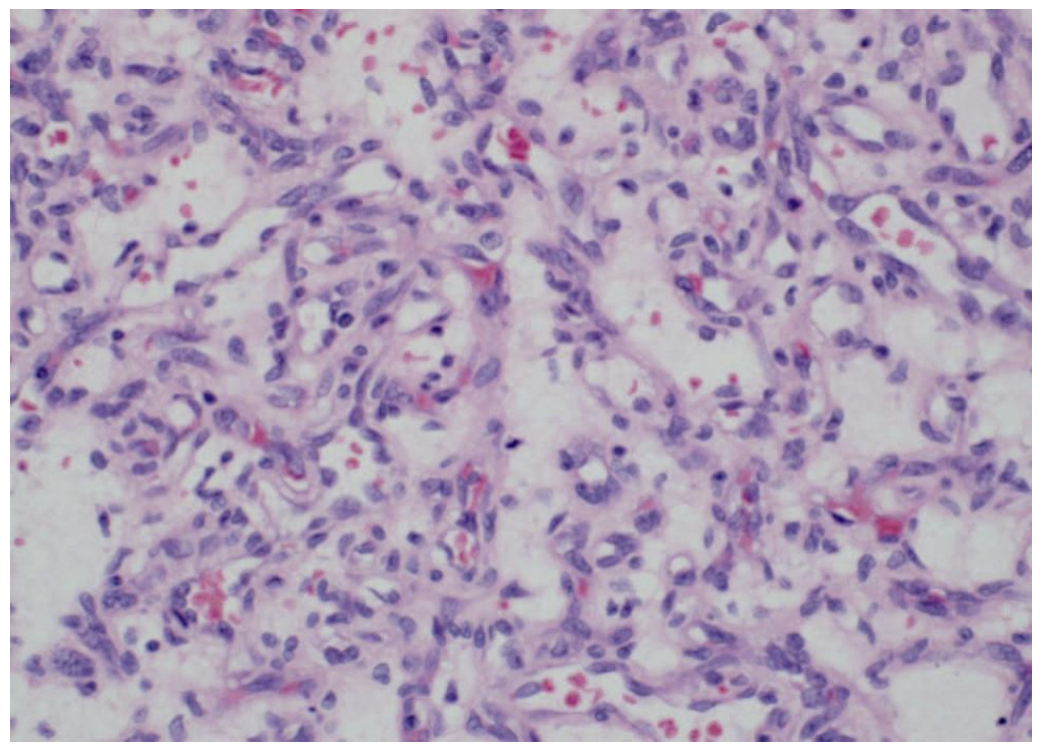

Figure 2: Hematoxylin and Eosin stain showing capillary sized vascular spaces lined by flat endothelial cells containing red blood cells (original magnification x400). [12] Zaidi S N, Fathaddin A A. Testicular capillary hemangioma - A case report of a rare tumor; Indian Journal of Pathology \&amp; Microbiology. 2012; 55(2): 557 559; http://www.ijpmonline.org/article.asp?issn=0377-

4929; year $=2012 ;$ volume $=55$;issue $=4 ;$ spage $=557$; epage $=559$; aulast $=$ Zaidi Accessed 2019 Dec 06 under Open Access Publication and Creative Commons Licensing This is an open access article journal, and articles are distributed under the terms of the Creative Commons Attribution-Non-Commercial-Share Alike 4.0 License, which allows others to remix, tweak, and build upon the work non-commercially, as long as appropriate credit is given and the new creations are licensed under the identical terms.

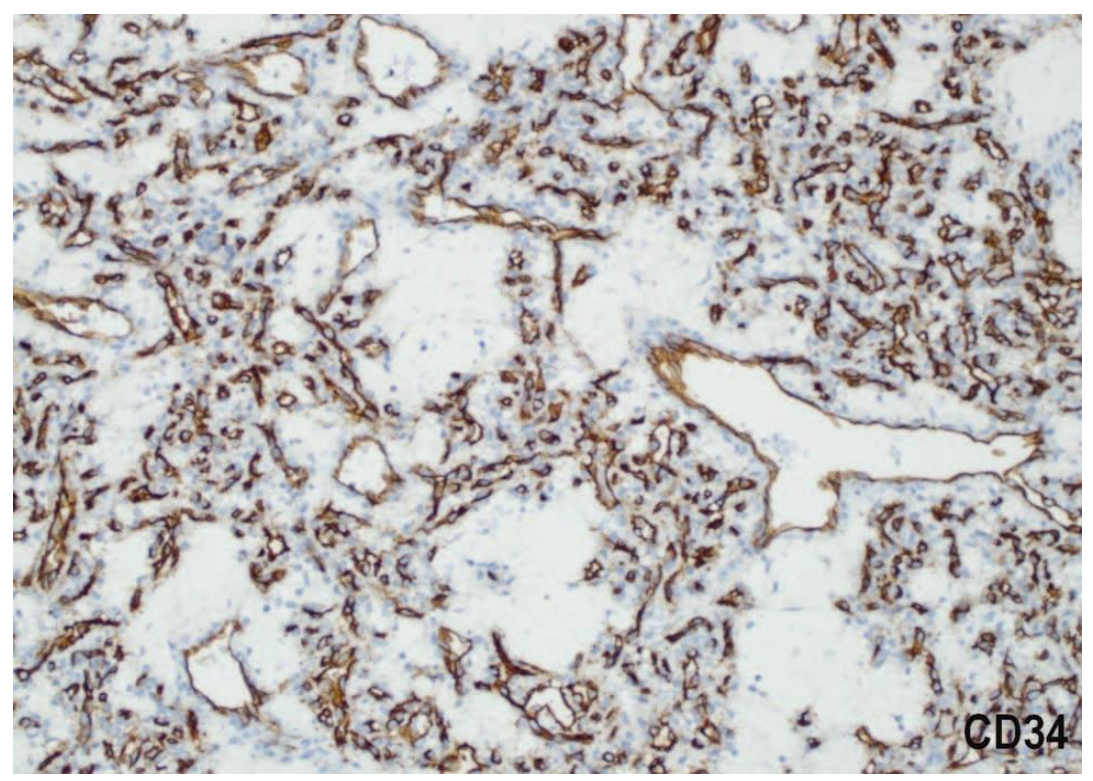

Figure 3: Immunohistochemical staining for CD 34 highlighting the endothelial cells lining the vascular spaces (Original magnification x200). Reproduced from: [12] Zaidi S N, Fathaddin A A. Testicular capillary hemangioma A case report of a rare tumor. Indian Journal of Pathology \& Microbiology. 2012; 55(2): 557 - 559 http://www.ijpmonline.org/article.asp?issn=03774929; year=2012; volume=55;issue=4; spage=557; epage=559; aulast=Zaidi Accessed 2019 Dec 06 
Bank and Mills [18] in 1990 reported a 29-yearold man who had an unusual vascular neoplasm which had arisen in his testis and which had mimicked adenomatoid tumour of the testis upon light microscopy examination. He had undergone orchidectomy and was alive, well, and diseasefree at his 3-year follow-up. The tumour which measured $2 \mathrm{~cm}$ did comprise of small tubules that were lined by mesothelial-like cells which contained uniform, vesicular nuclei. Nevertheless, some lumens contained erythrocytes and immunohistochemistry staining of the specimen showed that the luminal cells had exhibited positive staining for vimentin, Factor VIII-related antigen, and Ulex europaeus I lectin but they stained negatively with cytokeratin and epithelial membrane antigen (EMA). A cuff of musclespecific actin-positive cells were found around the luminal cell layer. Bank and Mills [18] iterated that the adenomatoid-like vascular neoplasm was more probably interpreted as histiocytoid (epithelioid) haemangioma. Even though some authors had considered lesions that were similar microscopically to represent a vascular variant of adenomatoid tumour, they would prefer to reserve the term "adenomatoid tumour" for microscopically appropriate proliferations which exhibit mesothelial features.

Passman et al. [13] retrospectively reviewed all surgical operations for testicular masses from June 1995 and June 2005. Patients who had testicular atrophy, germ cell tumours, infection, or torsion of the testis were excluded. The study did comprise of men who had undergone radical orchidectomy for suspected germ cell tumour but who had other final pathology, as well as those cases where testis sparing surgery was attempted based upon a presumed diagnosis of a benign lesion. Passman et al. [13] summarized their results as follows:

- They had identified 13 patients with lesions that were appropriate for the study and out of them 12 had palpable lesions and one did not have a palpable lesion.

- The lesions had been categorised as:

- Inflammatory (three were hyalinized fibrosis, two were sarcoidosis, one was chronic inflammation).

○ Cystic (one was epidermoid cyst, one was unilocular cyst).

- Benign neoplasms (two were adenomatoid tumours, one was Leydig cell tumour of testis, one was capillary haemangioma of testis).

- Malignant (one was lymphoma of testis).

- Based upon the pre-operative impression/diagnosis, testis-sparing surgical operation was attempted in eight out of the 13 lesions and this was successful in 6 cases where it was attempted. In the remaining 5 cases, testis sparing surgical operation was not attempted in view of the fact that the preoperative diagnosis or impression was that of a germ cell tumour of the testis.

- Testis sparing surgery was successfully undertaken with regard to 6 of the 13 patients with the testicular lesions.

\section{Passman et al. [13] made the following conclusions:}

- Testis-sparing surgery could be possible if there is sufficient suspicion of a benign lesion.

- In situations where frozen section pathology examination findings are equivocal, radical orchidectomy would be required.

- Testis-sparing surgical operation had been feasible with regard to highly selected cases. 
Venkatanarasimha et al. [19] reported a 22-yearold man who had presented with a 2-month history of right testicular discomfort. His clinical examination demonstrated a non-tender right testicular mass. He had undergone bilateral orchidopexy when he was 10 years old. The results of his serum tumour markers of Beta Human Chorionic Gonadotrophin, alpha fetoprotein, and lactate dehydrogenase were within normal range. He had ultrasound scan of his scrotal contents which showed a $1.5 \mathrm{~cm}$, welldemarcated, predominantly hypo-echoic mass that had many foci of calcification within his right testis. Colour Doppler ultrasound scan examination did demonstrate equivocal sparse low-velocity flow within the testicular lesion. His left testis was normal. The ultrasound scan features of the right testicular mass were adjudged to be consistent with the diagnosis of germ cell tumour of the testis, with the non seminoma type of testicular tumour the more likely diagnosis in view of the calcification as well as atypical epidermoid cysts was considered as a differential diagnosis. He underwent transinguinal radical right orchidectomy. Pathology examination of the orchidectomy specimen showed a solitary intra-testicular haemorrhagic nodule that had measured $1.5 \mathrm{~cm}$ in diameter. Microscopy examination of the tumoral lesion showed that the tumour had comprised of thinwalled cavernous blood-filled vascular spaces. Many of the vascular spaces did contain intraluminal thrombi which contained focal discrete calcification. Additionally, areas of patchy discrete calcification of various sizes were observed within the stromal walls of the vascular spaces. Immunohistochemistry staining studies of the lesion had shown positive staining for CD31 and CD34 which did confirm the vascular nature of the tumour. Based upon the pathology examination of the specimen a diagnosis of cavernous haemangioma of the right testis was made.
Bialek et al. [1] reported a 23-year-old man who had noticed the upper part of his left testis had been characterized by increased density and irregular contours over the preceding 2 months. He denied having had any trauma and had been asymptomatic. His clinical examination demonstrated a hard non-tender, tumour that measured $2 \mathrm{~cm}$ in diameter with irregular contours, within the upper pole of his left testis. The rest of his intra-scrotal contents were normal. The results his of routine haematology and biochemistry blood tests as well as serum Beta Chorionic Gonadotrophin, alpha fetoprotein, and lactate dehydrogenase were within normal range. He had ultrasound scan of his scrotal contents which showed an oval lesion that measured 2.4 $\mathrm{cm}$ in diameter with slightly decreased echogenicity within the upper pole of his left testis (see figure 4). No calcifications, fibrosis, or foci of necrotic tissue were seen within the area of the lesion. The left testis was encompassed by about a $2 \mathrm{ml}$ of clear fluid. The lesion did appear to have infiltrated across the tunica albuginea next to the head of the left epididymis (see figure 5). The tumour had been characterized by very rich vasculature as well as very distinct blood flow within Color and power Doppler scans (see figures 6 and 7). The arrangement of the vessels did simulate that of a normal vascular pattern of the parenchyma of the testis. 3D ultrasound scan images were obtained with utilization of the freehand technique as well as Color Doppler option (see figure 8) and a three-dimensional reconstruction of the suspected lesion vasculature was undertaken (see figure 9). No other abnormalities were visualised in the ultrasound scan of the scrotum. A left sided trans-inguinal approach orchidectomy option was adopted and during the procedure it was found that macroscopic examination showed the upper pole of the left testis was bluish with regard to colour and it felt hard on palpation with uneven surface 
focally (see figure 10). In view of suspicion of a malignant tumour of the left testis a transinguinal radical orchidectomy with high ligation of the spermatic cord was undertaken. Macroscopic examination of the specimen showed a testis that measured $5 \mathrm{~cm} \times 2 \mathrm{~cm} \times 2 \mathrm{~cm}$ and the epididymis had measured $3 \mathrm{~cm} \times 1 \mathrm{~cm} \times 1 \mathrm{~cm}$ together with a part of the spermatic cord of $5 \mathrm{~cm}$ length. Two nodules that measured $0.3 \mathrm{~cm}$ with regard to diameter were observed on the outer surface of the testis. Upon sectioning of the tumoral mass, a greyish tumour that measured $1.2 \mathrm{~cm} \times 1 \mathrm{~cm} \times 1.5 \mathrm{~cm}$ which had extended up to the outer surface of the testis was found. Microscopy examination of the tumour showed features that were consistent with Haemangioma capillare multifocale testis (multifocal capillary haemangioma of the testis). Immunohistochemistry staining of the tumoral mass showed positive staining for CD31, CD34, and vimentin, and negative staining for $\mathrm{CK} \mathrm{MNF}$ 116, FVIII, mesothelial cells, calretinin, and MIB-1 was equal to $8.4 \%$ (see figure 11). Bialek et al. [1] stated the following:

- Up to the time of publication of their article in 2016 only 55 similar cases of tumour (haemangioma of the testis) had been reported in the literature and out of these reports only one case series had involved 8 tumours [2], [8], [17], [20].

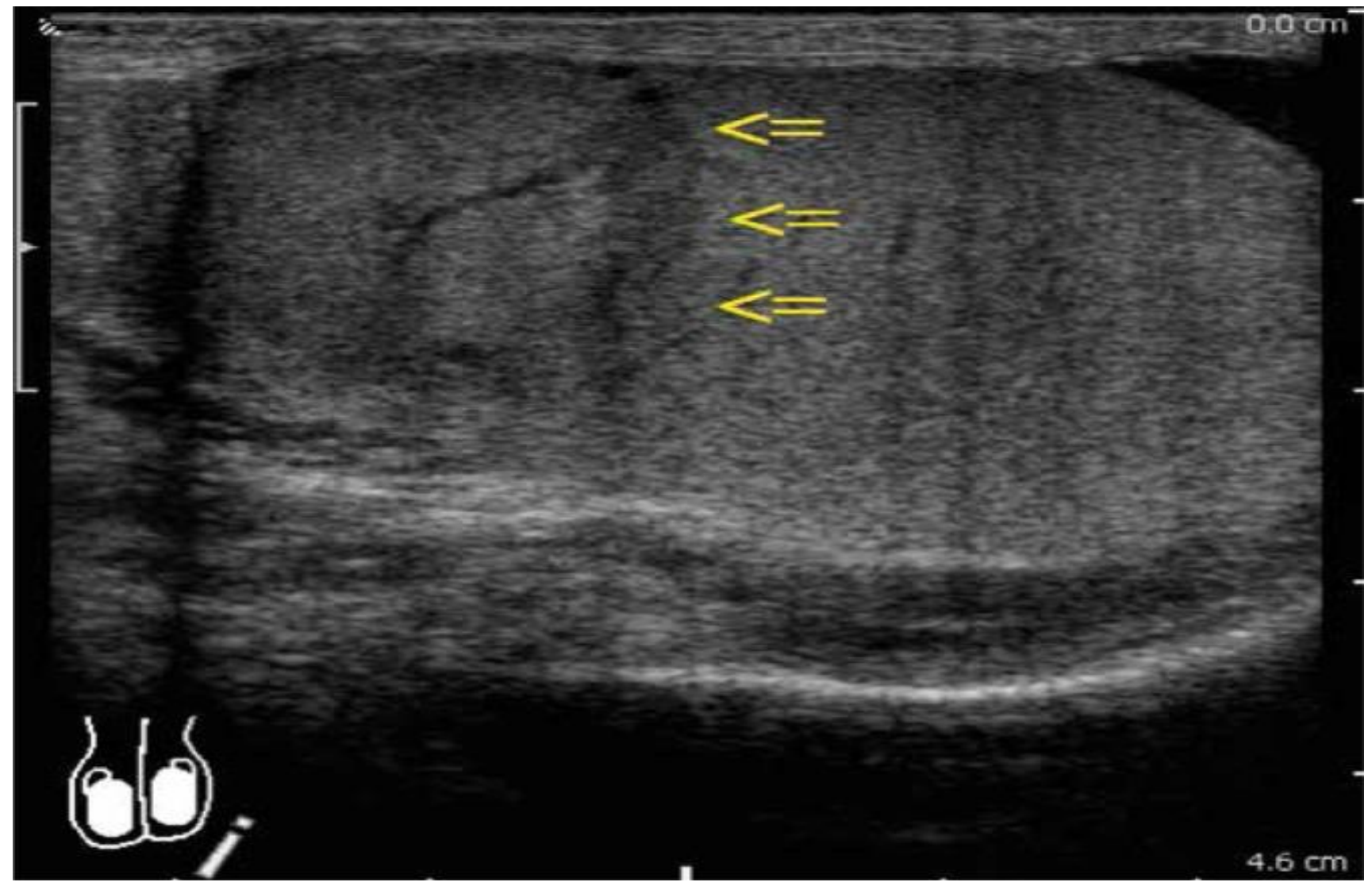

Figure 4: Ultrasound scan. $12 \mathrm{MHz}$ linear probe. Left testis. A lesion with a slightly decreased echogenicity is visible in its upper pole; Reproduced from: [1] Bialek W, Rudzki S, Wronecki L. Capillary haemangioma of the testis; A case report of a rare benign tumor. Journal of Ultrasonography. 2016 Mar; 16(64): 87 - 93. DOI: 10.15557/JoU.2016.0009 
https://www.ncbi.nlm.nih.gov/pmc/articles/PMC4834374/ under Copyright (c) Polish Ultrasound Society. Published by Medical Communications Sp. z. o. o. All rights reserved. This is an open-access article distributed under the terms of the Creative Commons Attribution-NonCommercial-NoDerivatives License (CC BY-NC-ND). Reproduction is permitted for personal, educational, non-commercial use, provided the original article is in whole, unmodified, and properly cited.

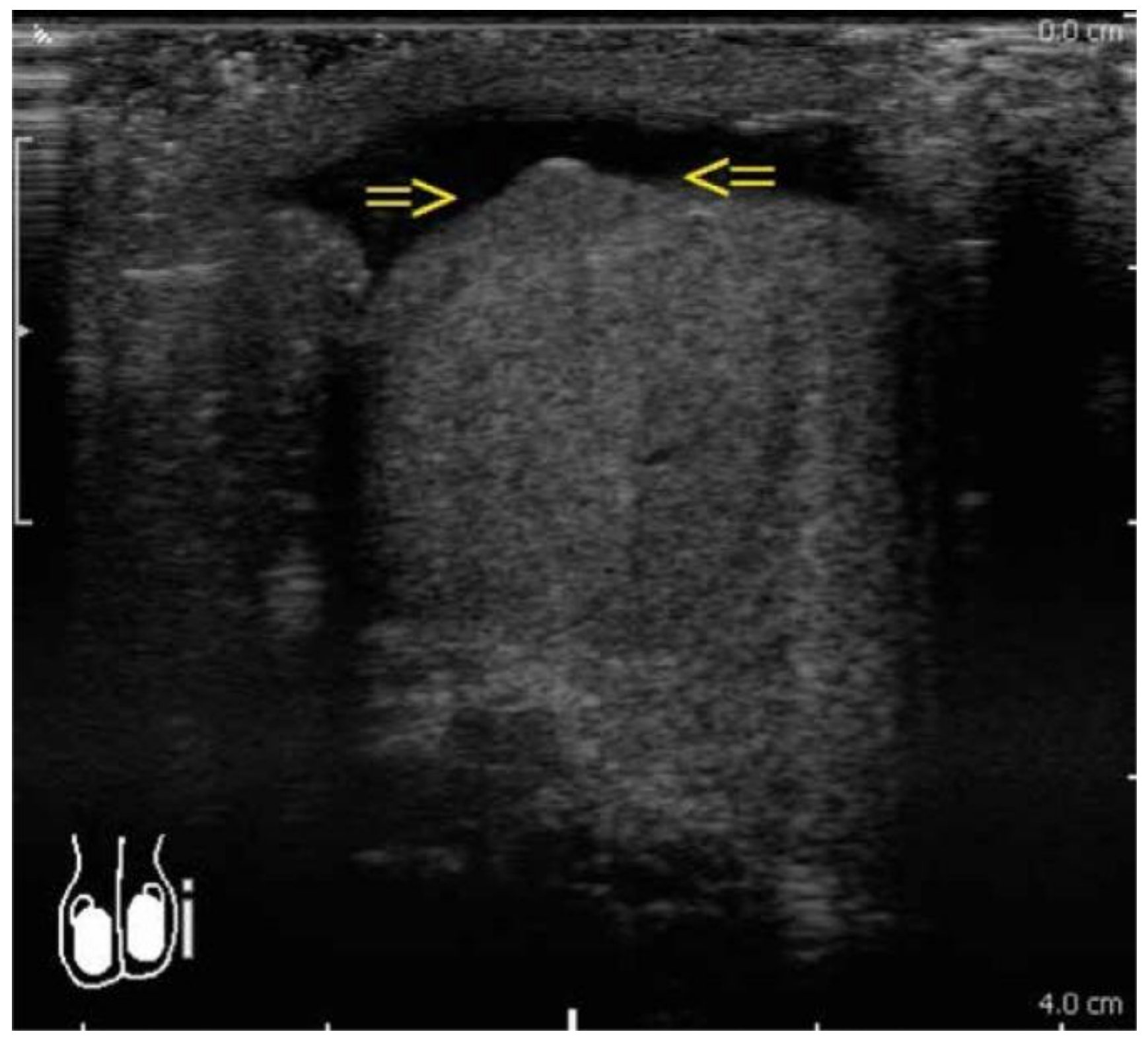

Figure 5: Ultrasound scan. $12 \mathrm{MHz}$ linear probe. Irregular contours of the upper pole of the left test is which suggest infiltration of the tunica albuginea; Reproduced from: [1] Bialek W, Rudzki S, Wronecki L. Capillary haemangioma of the testis. A case report of a rare benign tumor. Journal of Ultrasonography. 2016 Mar; 16(64): 87 - 93. DOI: $10.15557 / J o U .2016 .0009$

https://www.ncbi.nlm.nih.gov/pmc/articles/PMC4834374/ under Copyright (c) Polish Ultrasound Society. Published by Medical Communications Sp. z. o. o. All rights reserved. This is an open-access article distributed 
under the terms of the Creative Commons Attribution-Non-Commercial-No-Derivatives License (CC BY-NC-ND). Reproduction is permitted for personal, educational, non-commercial use, provided the original article is in whole, unmodified, and properly cited.

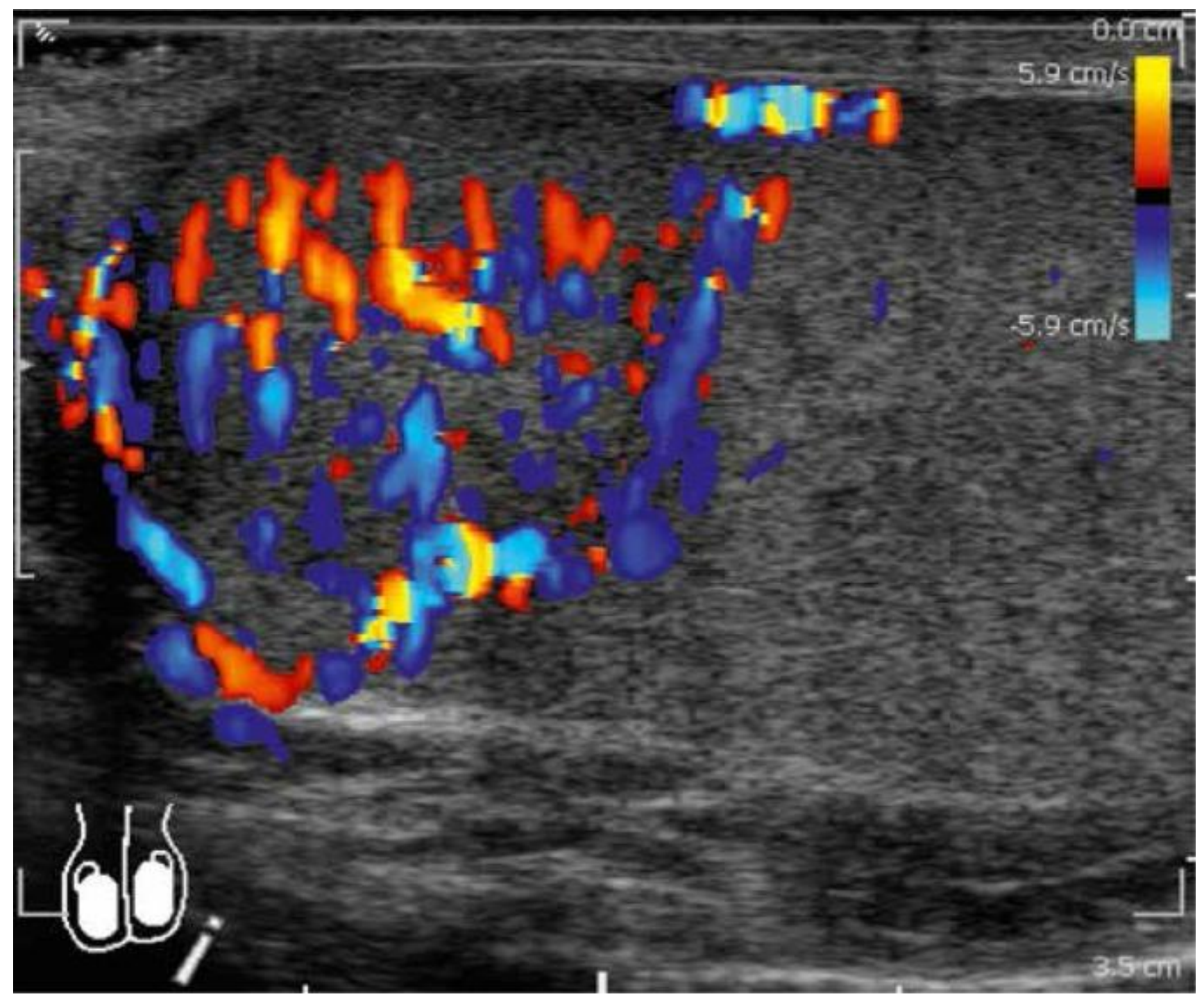

Figure 6: Ultrasound scan with color Doppler imaging. The vasculature of the upper pole of the left testis is distinctly larger than the remaining testicular tissue; Reproduced from: [1] Bialek W, Rudzki S, Wronecki L. Capillary haemangioma of the testis. A case report of a rare benign tumor. Journal of Ultrasonography. 2016 Mar; 16(64): 87 - 93. DOI: 10.15557/JoU.2016.0009

https://www.ncbi.nlm.nih.gov/pmc/articles/PMC4834374/ under Copyright (C) Polish Ultrasound Society. Published by Medical Communications Sp. z. o. o. All rights reserved. This is an open-access article distributed under the terms of the Creative Commons Attribution-NonCommercial-NoDerivatives License (CC BY-NC-ND). Reproduction is permitted for personal, educational, non-commercial use, provided the original article is in whole, unmodified, and properly cited. 


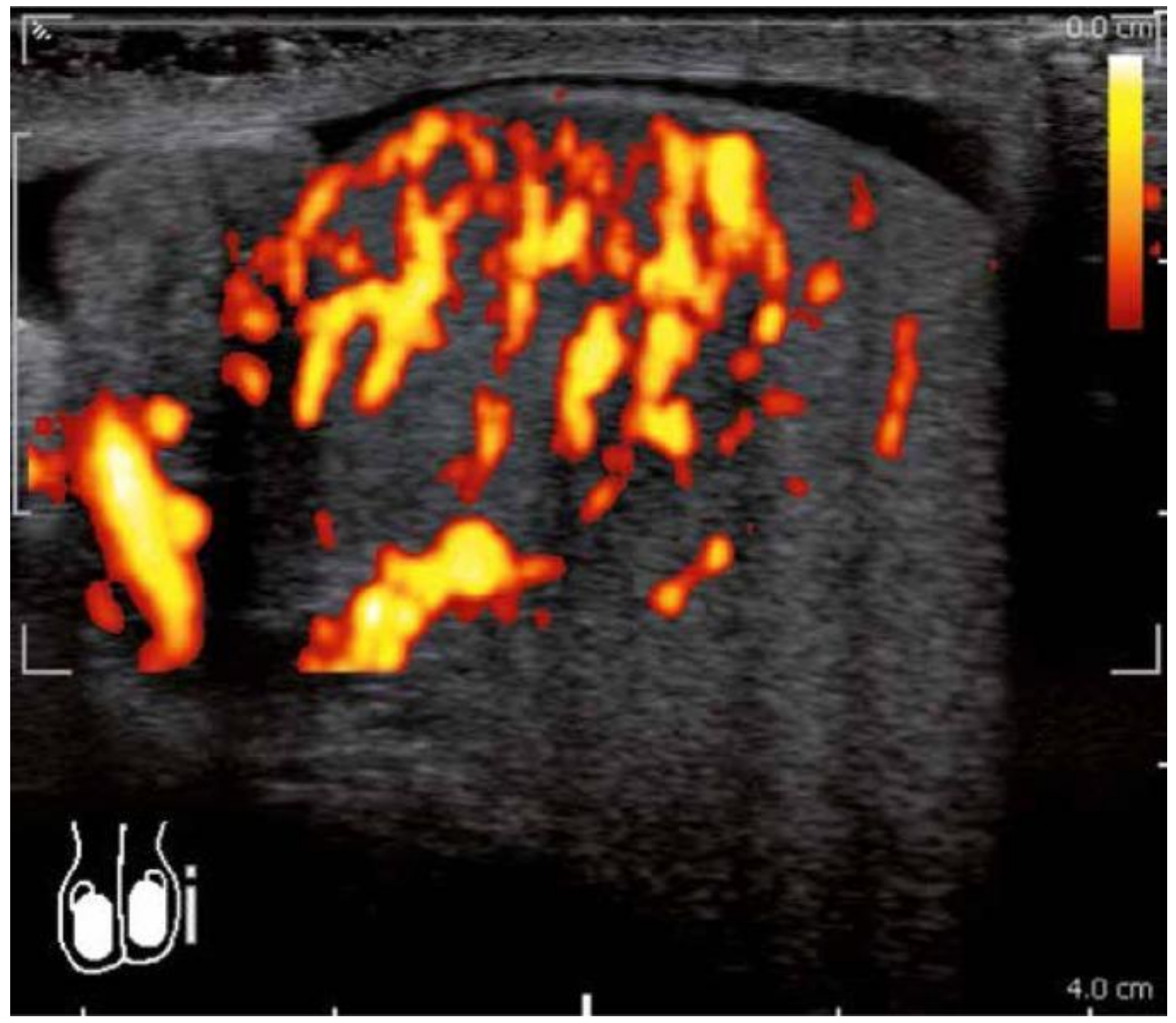

Figure 7: Ultrasound scan with power Doppler imaging. The examination confirms a significantly larger blood flow in the upper pole of the testis in the area of the previously found lesion; Reproduced from: [1] Bialek W, Rudzki S, Wronecki L. Capillary haemangioma of the testis. A case report of a rare benign tumor. Journal of Ultrasonography. 2016 Mar; 16(64): 87 - 93. DOI: 10.15557/JoU.2016.0009

https://www.ncbi.nlm.nih.gov/pmc/articles/PMC4834374/ under Copyright (C) Polish Ultrasound Society. Published by Medical Communications Sp. z. o. o. All rights reserved. This is an open-access article distributed under the terms of the Creative Commons Attribution-NonCommercial-NoDerivatives License (CC BY-NC-ND). Reproduction is permitted for personal, educational, non-commercial use, provided the original article is in whole, unmodified, and properly cited. 


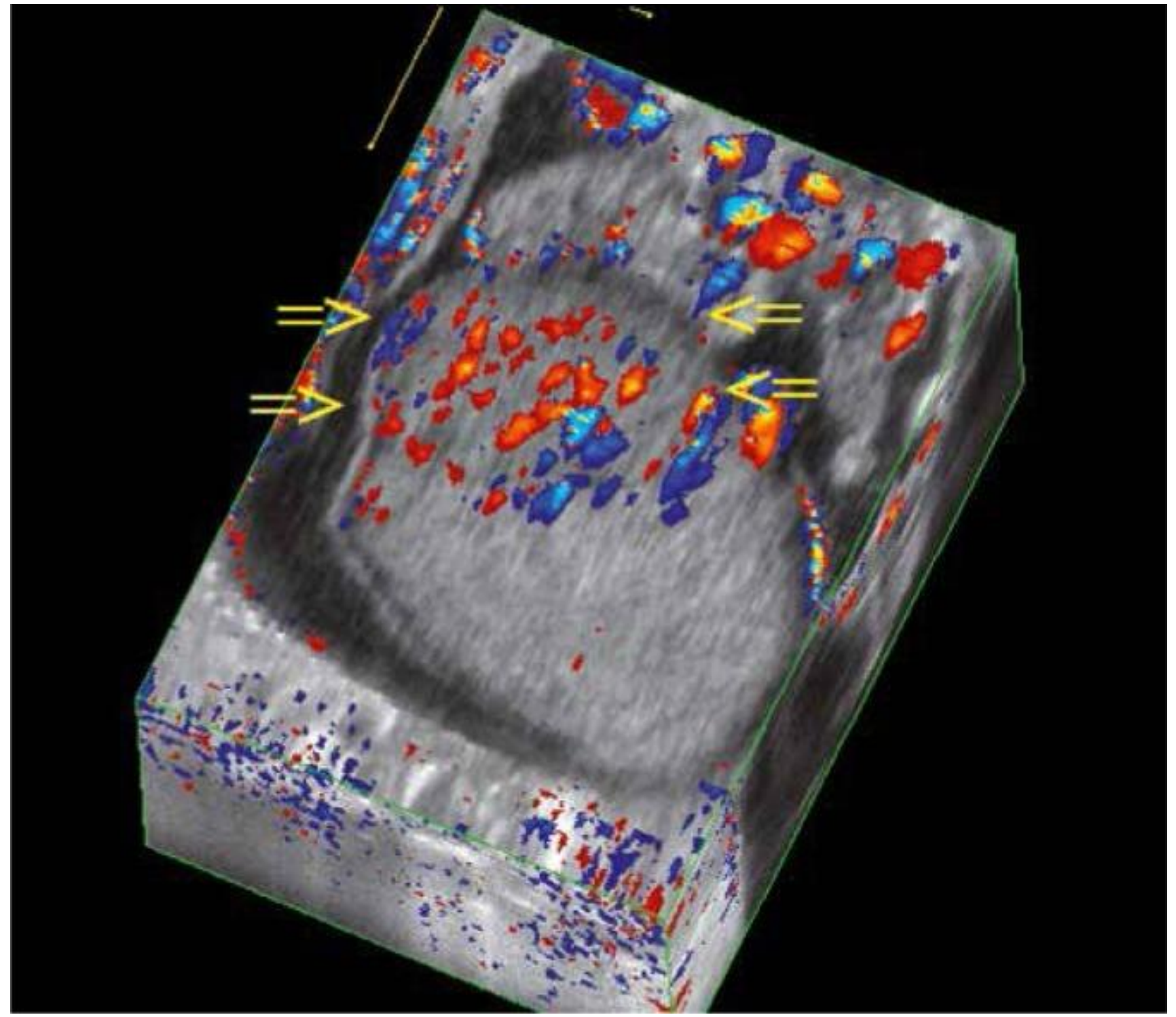

Figure 8: 3D ultrasound scan. Three-dimensional reconstruction of the left testis using color Doppler imaging; Reproduced from: [1] Bialek W, Rudzki S, Wronecki L. Capillary haemangioma of the testis. A case report of a rare benign tumor. Journal of Ultrasonography. 2016 Mar; 16(64): 87 - 93. DOI: 10.15557/JoU.2016.0009 https://www.ncbi.nlm.nih.gov/pmc/articles/PMC4834374/ under Copyright (c) Polish Ultrasound Society. Published by Medical Communications Sp. z. o. o. All rights reserved. This is an open-access article distributed under the terms of the Creative Commons Attribution-NonCommercial-NoDerivatives License (CC BY-NC-ND). Reproduction is permitted for personal, educational, non-commercial use, provided the original article is in whole, unmodified, and properly cited. 


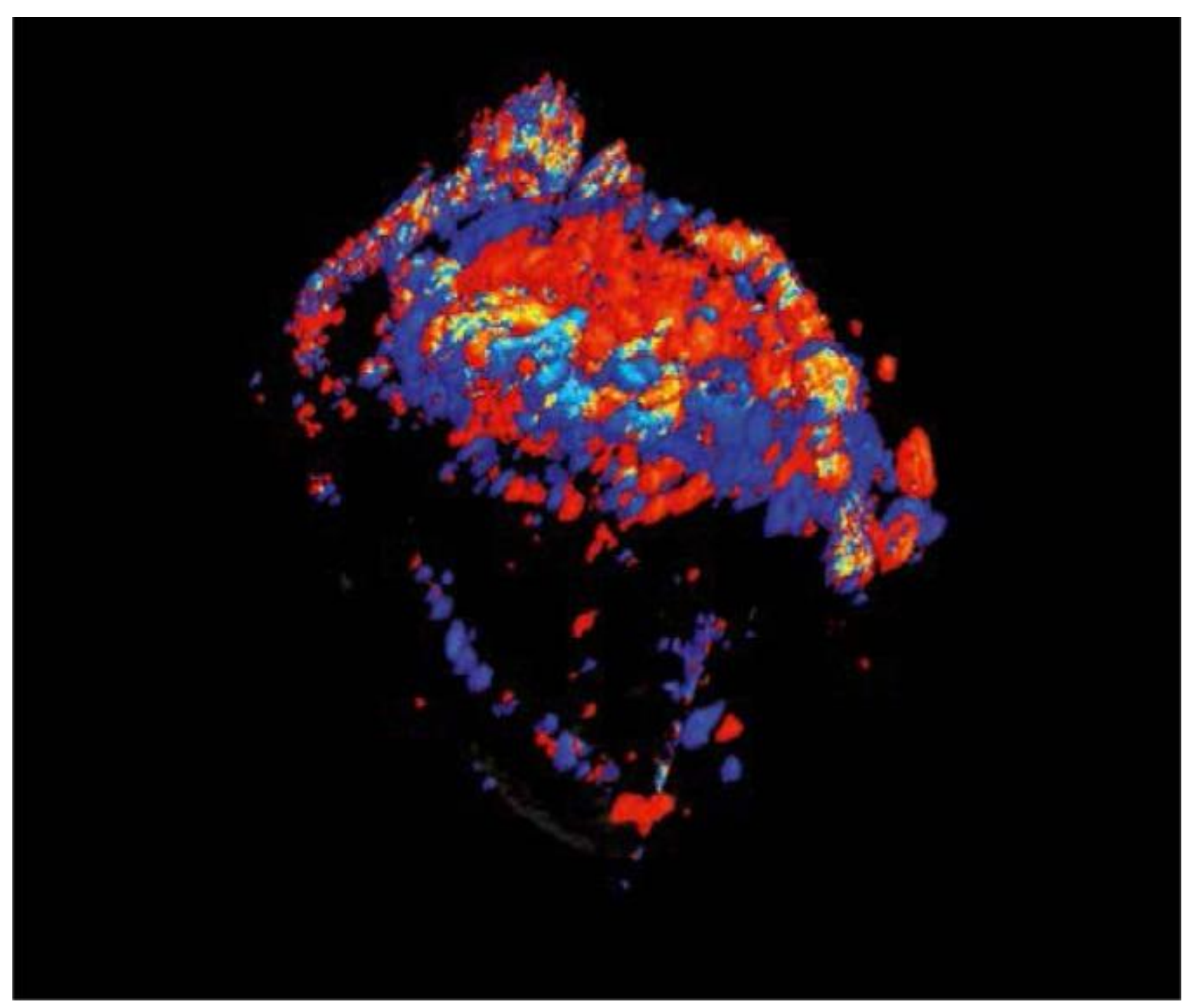

Figure 9: 3D ultrasound scan. Three-dimensional reconstruction of the vasculature of the suspicious lesion located in the upper pole of the left testis allows for the determination of its precise topography; Reproduced from: [1] Bialek W, Rudzki S, Wronecki L. Capillary haemangioma of the testis. A case report of a rare benign tumor. Journal of Ultrasonography. 2016 Mar; 16(64): 87 - 93. DOI: 10.15557/JoU.2016.0009 https://www.ncbi.nlm.nih.gov/pmc/articles/PMC4834374/ under Copyright (c) Polish Ultrasound Society. Published by Medical Communications Sp. z. o. o. All rights reserved. This is an open-access article distributed under the terms of the Creative Commons Attribution-NonCommercial-NoDerivatives License (CC BY-NC-ND). Reproduction is permitted for personal, educational, non-commercial use, provided the original article is in whole, unmodified, and properly cited. 


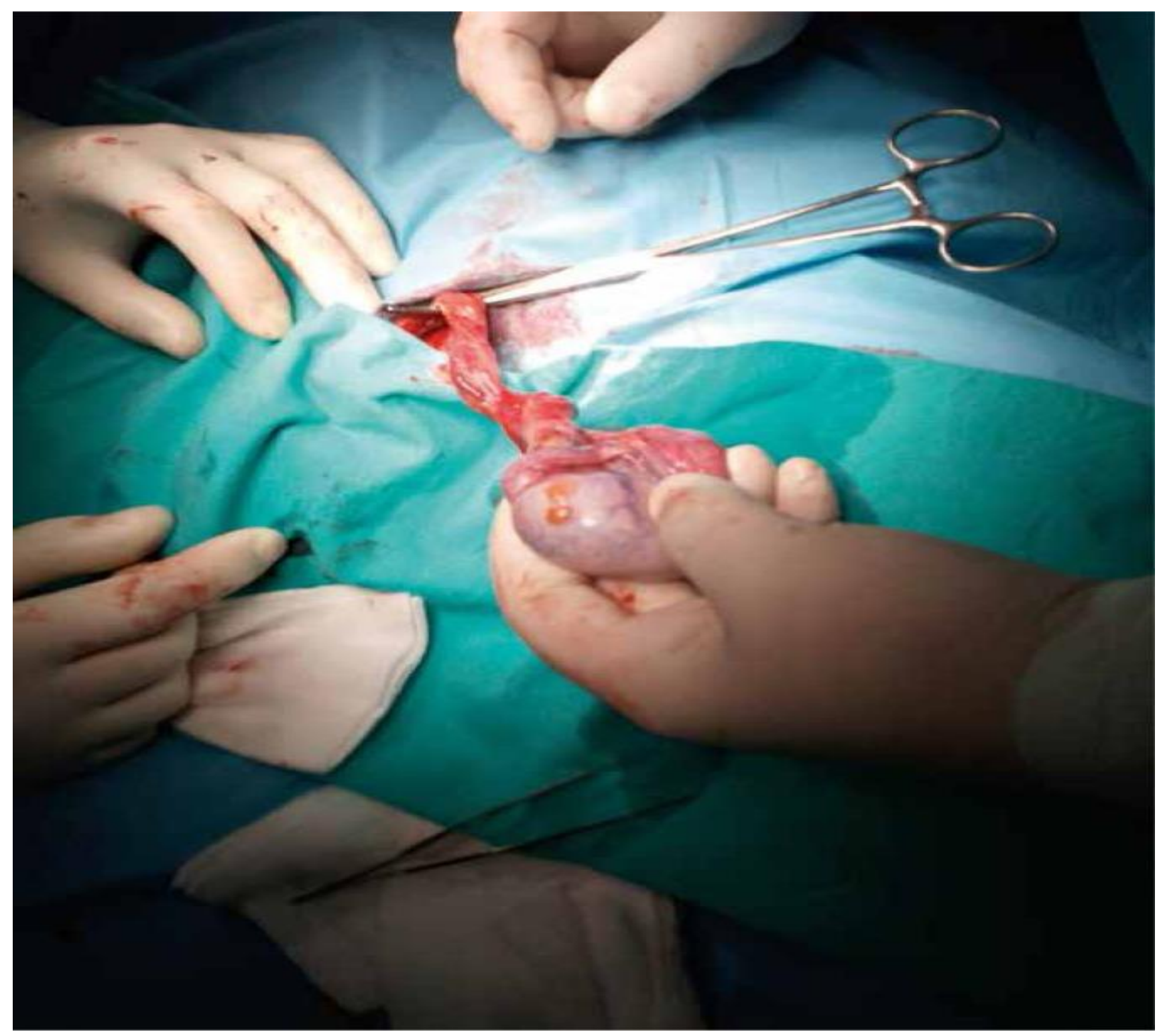

Figure 10: Intraoperative image of the upper pole of the testis with an enhanced vascular pattern and bluish color. Two lesions resembling testicular appendages were found in the place where infiltration of the tunica albuginea had been suspected.

Reproduced from: [1] Bialek W, Rudzki S, Wronecki L. Capillary haemangioma of the testis. A case report of a rare benign tumor. Journal of Ultrasonography. 2016 Mar; 16(64): 87 - 93. DOI: 10.15557/JoU.2016.0009 https://www.ncbi.nlm.nih.gov/pmc/articles/PMC4834374/ under Copyright (C) Polish Ultrasound Society. Published by Medical Communications Sp. z. o. o. All rights reserved. This is an open-access article distributed under the terms of the Creative Commons Attribution-NonCommercial-NoDerivatives License (CC BY-NC-ND). Reproduction is permitted for personal, educational, non-commercial use, provided the original article is in whole, unmodified, and properly cited. 

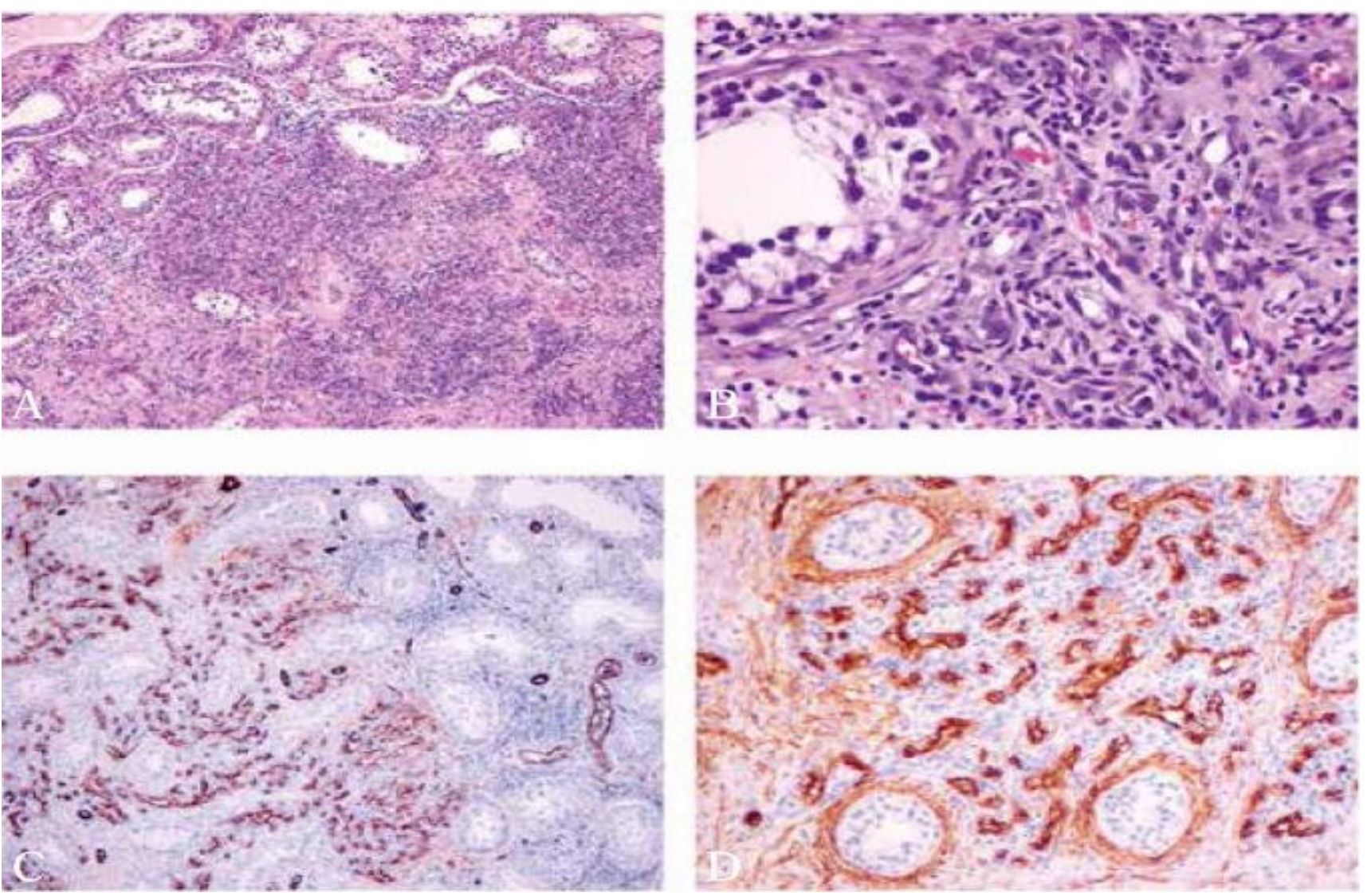

Figure 11: Capillary haemangioma of the testis: A. benign tumor composed of a proliferation of capillary-size vessels in the testis parenchyma (hematoxylin and eosin, original magnification x 10); B. numerous capillary-size vessels lined by endothelial cells without anaplastic features (hematoxylin and eosin, original magnification $\mathrm{x} 40$ ); C. Endothelial cells showing prominent immunostaining for CD31 (original magnification x 10); D. Endothelial cells showing prominent immunostaining for CD34 (original magnification x 20). Reproduced from: [1] Bialek W, Rudzki S, Wronecki L. Capillary haemangioma of the testis. A case report of a rare benign tumor. Journal of Ultrasonography. 2016 Mar; $16(64): \quad 87 \quad-\quad 93 . \quad$ DOI: $10.15557 / J o U .2016 .0009$ https://www.ncbi.nlm.nih.gov/pmc/articles/PMC4834374/ under Copyright (c) Polish Ultrasound Society. Published by Medical Communications Sp. z. o. o. All rights reserved. This is an open-access article distributed under the terms of the Creative Commons Attribution-NonCommercial-NoDerivatives License (CC BY-NC-ND). Reproduction is permitted for personal, educational, non-commercial use, provided the original article is in whole, unmodified, and properly cited.

Tepeneu et al. [21] reported a 15-year-old boy who had presented with a 6-days history of painful left testis without any vomiting, fever or dysuria. He had ultrasound scan of the scrotal contents under the suspicion of old torsion of the testis which confirmed the diagnosis of torsion of his left testis (see figures 12 and 13). He underwent emergency surgical exploration of the left testis which revealed that his left testis was necrotic after a 360 degree torsion (see figure 14) and orchidectomy was undertaken. Pathology examination of the specimen demonstrated a complete ischaemic infarction of the parenchyma of the testis as part of a ruptured intra-testicular haemangioma (see figure 15 and figure 16). Tepeneu et al. [21] documented the ensuing:

- Haemangioma of the testis is very uncommon and it typically does occur in males who are younger than 20 years of age. 
- Haemangiomas of the testis tend to have similar ultrasound scan and magnetic resonance imaging appearance to that of malignant tumours of the testis especially that of seminoma of the testis.

- Clinicians need to be aware of this rare entity of haemangioma of the testis, in view of the fact that clinical examination and radiology imaging studies do not often suffice with regard to arriving at a correct diagnosis.

- The association between torsion of the testis and haemangioma of the testis is rare in children.

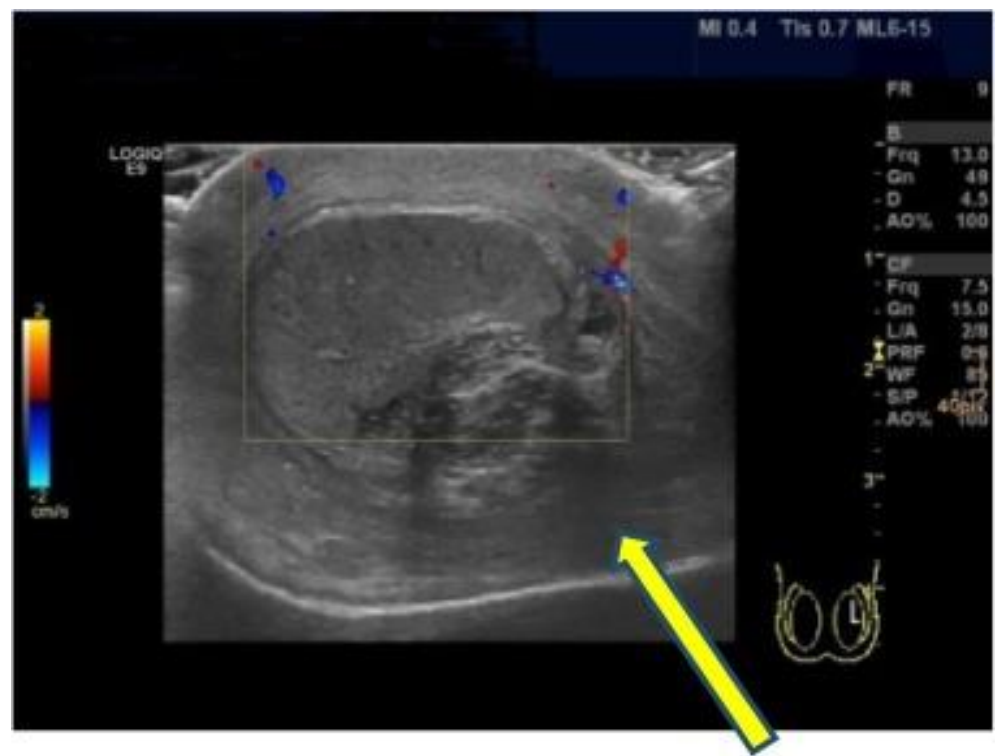

Figure 12: The sonographic aspect of the left testicle without central perfusion with an altered structure (GE Logiq E9 ultrasound equipment. Reproduced from: [21] Tepeneu F, Krafka K, Meglic S, Rogatsch H, Fasching G. Testicular cavernous hemangioma associated with testicular torsion - case report and review of the literature. International Journal of Surgery Case Reports. 2018; 49: 247 - 250. https://doi.org/10.1016/j.ijscr.2018.06.019 //www.sciencedirect.com Under Copyright (c) 2018 The Authors This is an open access article under the CC BY-NCND license (http://creativecommons.org/licenses/by-nc-nd/4.0/).

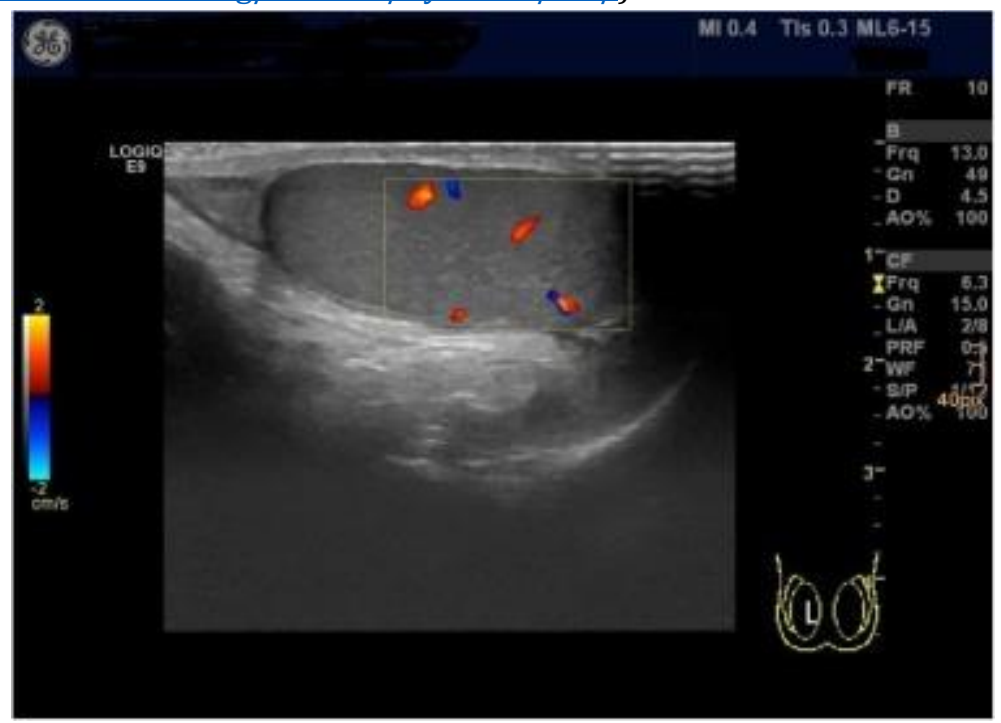

Figure 13: For comparison the sonographic aspect of the healthy right testicle with central perfusion and with a normal structure; Reproduced from: [21] Tepeneu F, Krafka K, Meglic S, Rogatsch H, Fasching G. Testicular 
cavernous hemangioma associated with testicular torsion - case report and review of the literature. International Journal of Surgery Case Reports. 2018; 49: 247 - 250. https://doi.org/10.1016/j.ijscr.2018.06.019 //www.sciencedirect.com Under Copyright (c) 2018 The Authors This is an open access article under the CC BY-NCND license (http://creativecommons.org/licenses/by-nc-nd/4.0/).

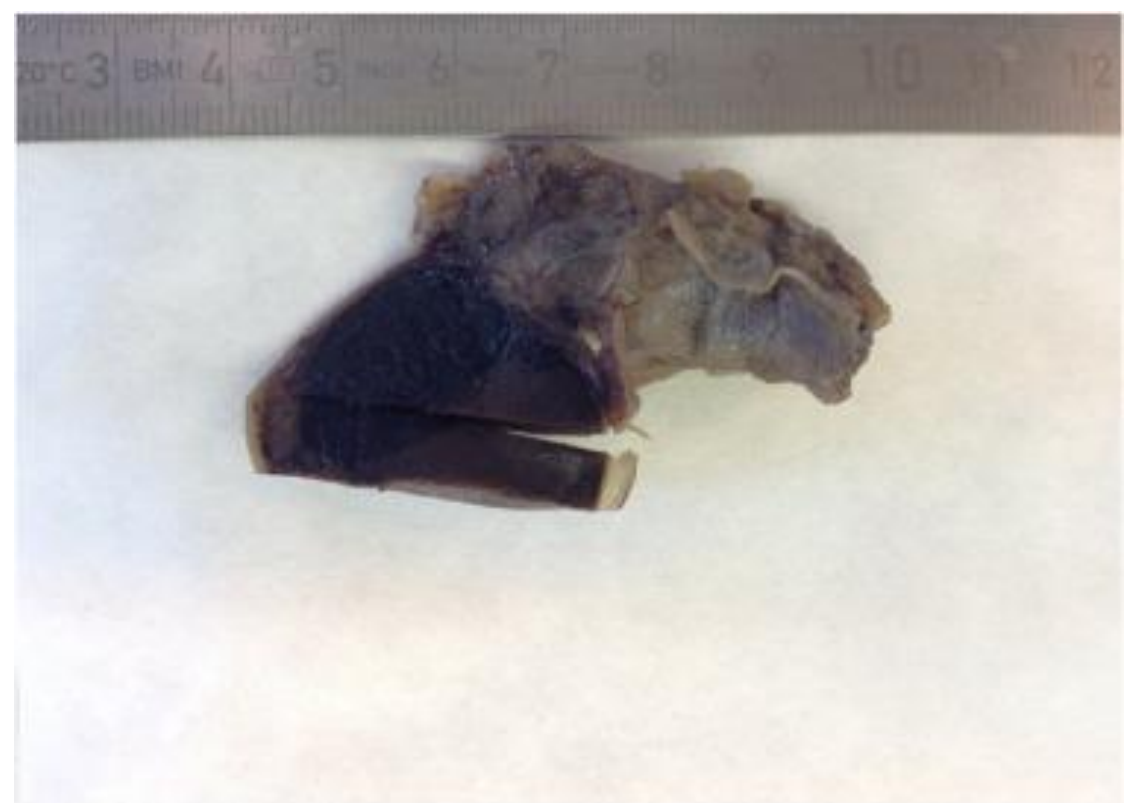

Figure 14: The macroscopic aspect of the removed testicle and spermatic cord.

[21] Tepeneu F, Krafka K, Meglic S, Rogatsch H, Fasching G. Testicular cavernous hemangioma associated with testicular torsion - case report and review of the literature. International Journal of Surgery Case Reports. 2018; 49: 247 - 250. https://doi.org/10.1016/j.ijscr.2018.06.019//www.sciencedirect.com Under Copyright (C) 2018 The Authors This is an open access article under the CC BY-NC-ND license (http://creativecommons.org/licenses/by-nc-nd/4.0/).

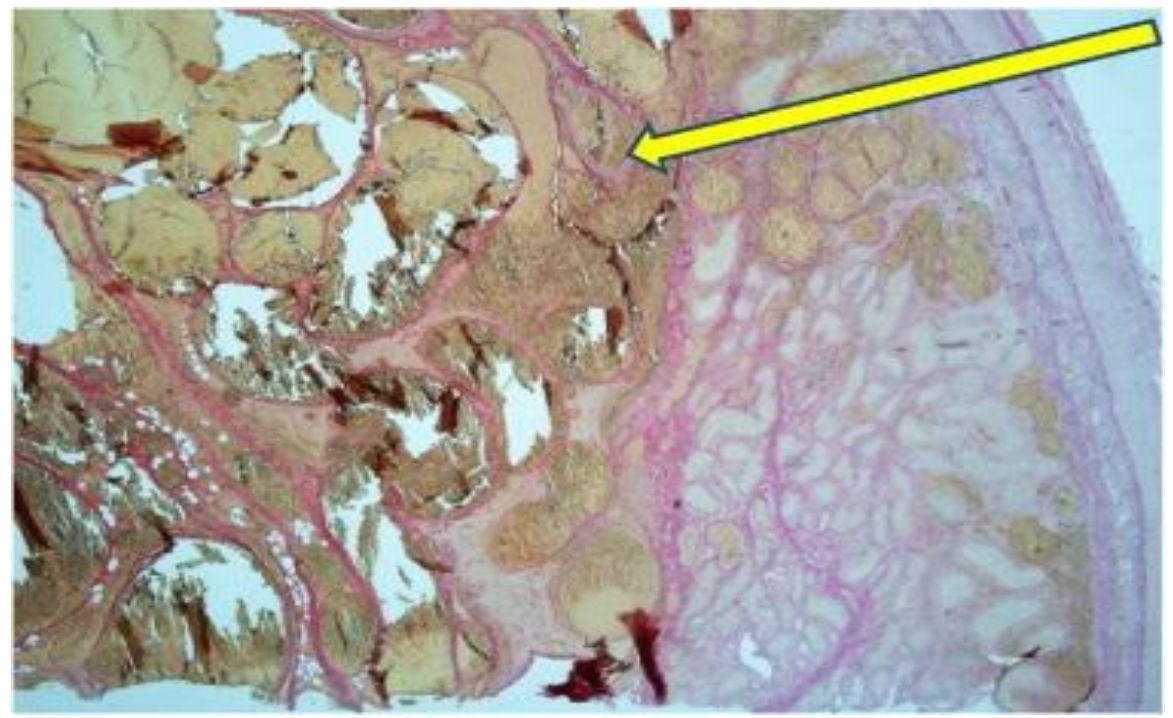

Figure 15: Verhoef-Van Gieson stain (20x magnification) - Histological aspect of the hemangioma. Reproduced from: [21] Tepeneu F, Krafka K, Meglic S, Rogatsch H, Fasching G. Testicular cavernous hemangioma associated 
with testicular torsion - case report and review of the literature. International Journal of Surgery Case Reports. 2018; 49: 247 - 250. https://doi.org/10.1016/j.ijscr.2018.06.019//www.sciencedirect.com under Copyright (C) 2018 The Authors This is an open access article under the CC BY-NC-ND license (http://creativecommons.org/licenses/by-nc-nd/4.0/).

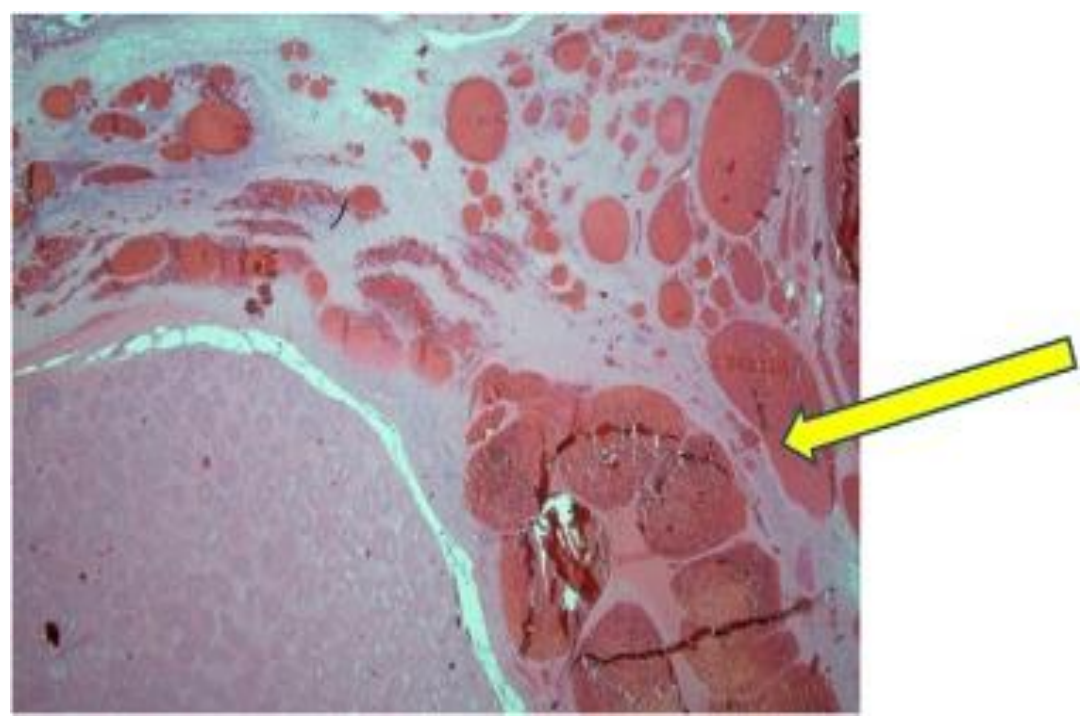

Figure 16: Hematoxylin and eosin stain (20x magnification)- Histological aspect of the hemangioma. Reproduced from: [21] Tepeneu F, Krafka K, Meglic S, Rogatsch H, Fasching G. Testicular cavernous hemangioma associated with testicular torsion - case report and review of the literature. International Journal of Surgery Case Reports. 2018; 49: 247 - 250. https://doi.org/10.1016/j.ijscr.2018.06.019//www.sciencedirect.com under Copyright (C) 2018 The Authors This is an open access article under the CC BY-NC-ND license (http://creativecommons.org/licenses/by-nc-nd/4.0/). Abda et al [22] reported a 34-year-old man who had manifested with a 4-days history of right hemiscrotal pain. He did not have any history of trauma, infection, or previous surgery. He only had polyuria. His clinical examination revealed a normal looking scrotum without any evidence of a focal tenderness or a palpable mass. The results of his routine urinalysis, microscopy and culture as well as his routine haematology blood tests were normal. He had ultrasound scan of his scrotal contents which revealed a $5 \mathrm{~mm} \times 3 \mathrm{~mm}$ x $4 \mathrm{~mm}$ homogenously hypo-echoic lesion within the posterior superior aspect of his right testis (see figure $17 \mathrm{~A}$, and 17B) which had increased internal flow on Colour Doppler imaging (see figure 17C). A small right hydrocele was visualised. The results of his serum tumour markers including Beta Human Chorionic Gonadotrophin, alpha fetoprotein, and lactate

dehydrogenase were normal. He had computed tomography (CT) of thorax, abdomen and pelvis which did not reveal any metastasis or suspicious lymph node enlargement. He underwent right radical orchidectomy. Macroscopic examination of the specimen showed a 4-mm red intraparenchymal nodule of the testis which had abutted the tunica albuginea. Histopathology examination of the specimen showed features that rendered a final diagnosis of benign haemangioma. He had remained well up to the time of the report of his case. Abda et al. [22] iterated that: it has been stipulated that haemangiomas of the testis are rare benign vascular tumours that arise from the inner layer of the tunica albuginea that serves as the conduit between the parenchyma of the testis and its supplying blood vessels and lymphatics [23]. 

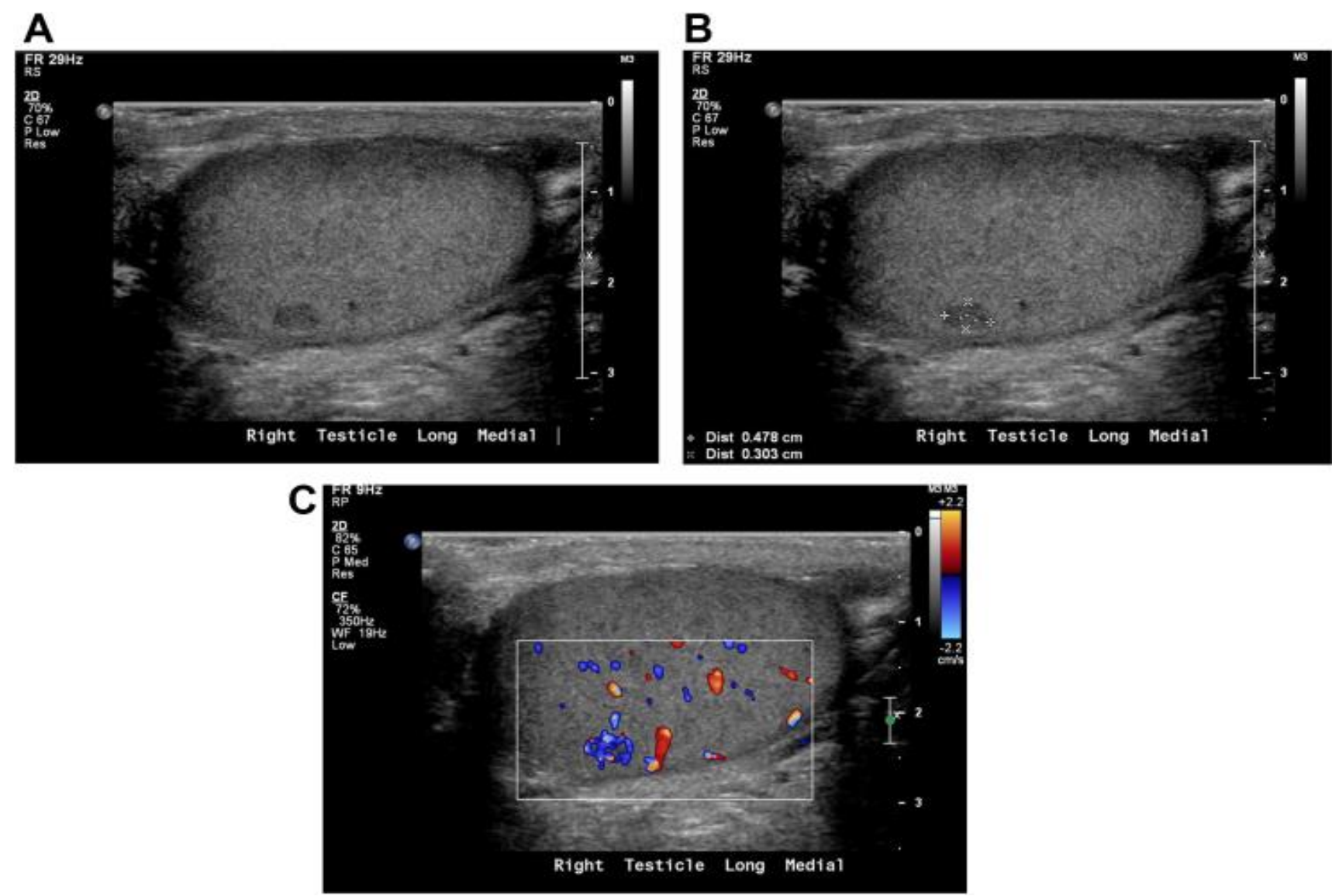

Figure 17: Testicular hemangioma in a 34-year-old man. (A and B). Sagittal grayscale ultrasound images of the right testicle show a hypoechoic intratesticular mass located within the posterior superior pole, measuring $5 \times 3$ mm. (C) Sagittal color Doppler ultrasound image of the right testicle demonstrates blood flow within the intratesticular mass. Reproduced from: [22] Abda R B, Bess D, Nieves-Robbins N. testicular hemangioma mimicking a malignant neoplasm. Radiology Case Reports 2016 Jun; 11(2): 121 - 123. DOI: 10.1016/j.radcr.2015.12.005 https://www.ncbi.nlm.nih.gov/pmc/articles/PMC4878950/ Accessed 2019 Dec 07 Copyright (C) 2016 The Authors This is an open access article under the CC BY-NC-ND license (http://creative commons.org/licenses/by-nc-nd/4.0/)

Liu et al [23] reported a 42-year-old man who had manifested with sudden onset of left testicular fullness over the preceding 3 months. He was asymptomatic otherwise. His clinical examination demonstrated a palpable non-tender, left testicular mass that measured $3 \mathrm{~cm} \times 2,5 \mathrm{~cm}$. The left testis was noted to be swollen as well as stiff. The epididymis and spermatic cord were observed to be normal. The results of his routine urine tests, haematology, and biochemistry blood tests were normal as well as the results of his serum Beta Human Chorionic Gonadotrophin, and alpha fetoprotein were normal. He had ultrasound scan of his scrotal contents which showed a roundish, well-demarcated, hypo-echoic mass within his left testis (see figure 18) and many calcifications within the mass. The mass did demonstrate blood flow upon colour Doppler scanning (see figure 19). A provisional diagnosis of teratoma of the testis was made. He underwent trans-inguinal radical left orchidectomy. Nevertheless, pathology examination of the 
specimen demonstrated features that were thrombus organization and calcifications (see diagnostic of cavernous haemangioma with figure 20). Liu et al. [23] stated the following:

- To distinguish cavernous haemangioma of the testis from other common testicular tumours prior to surgical excision is not feasible.

- Doppler ultrasound scan is useful for the diagnosis of haemangiomas of the testis in that it does demonstrate the nature of the mass as well a it does differentiate it from other testicular neoplasms [9].

- Haemangiomas upon sonography scans do vary from hypo-echoic to hyper-echoic or they could be heterogeneous [10].

- Various sizes of calcification tend to be common and in their reported case they had misdiagnosed cavernous haemangioma of the testis as a teratoma of the testis.

- Up to the time of the report of their case all reported cases of vascular testicular tumours had demonstrated benign biological behaviour without any report of local recurrence or metastasis [17].

- Testis-sparing surgery could be undertaken if intra-operative examination of sections of representative tissue is possible [17].

- When a patient does manifest with a testicular mass where ultrasound scan does illustrate a mass with calcifications of varying sizes and negative tumour marker levels are obtained in their blood tests, a diagnosis of haemangioma of the testis could be rendered.

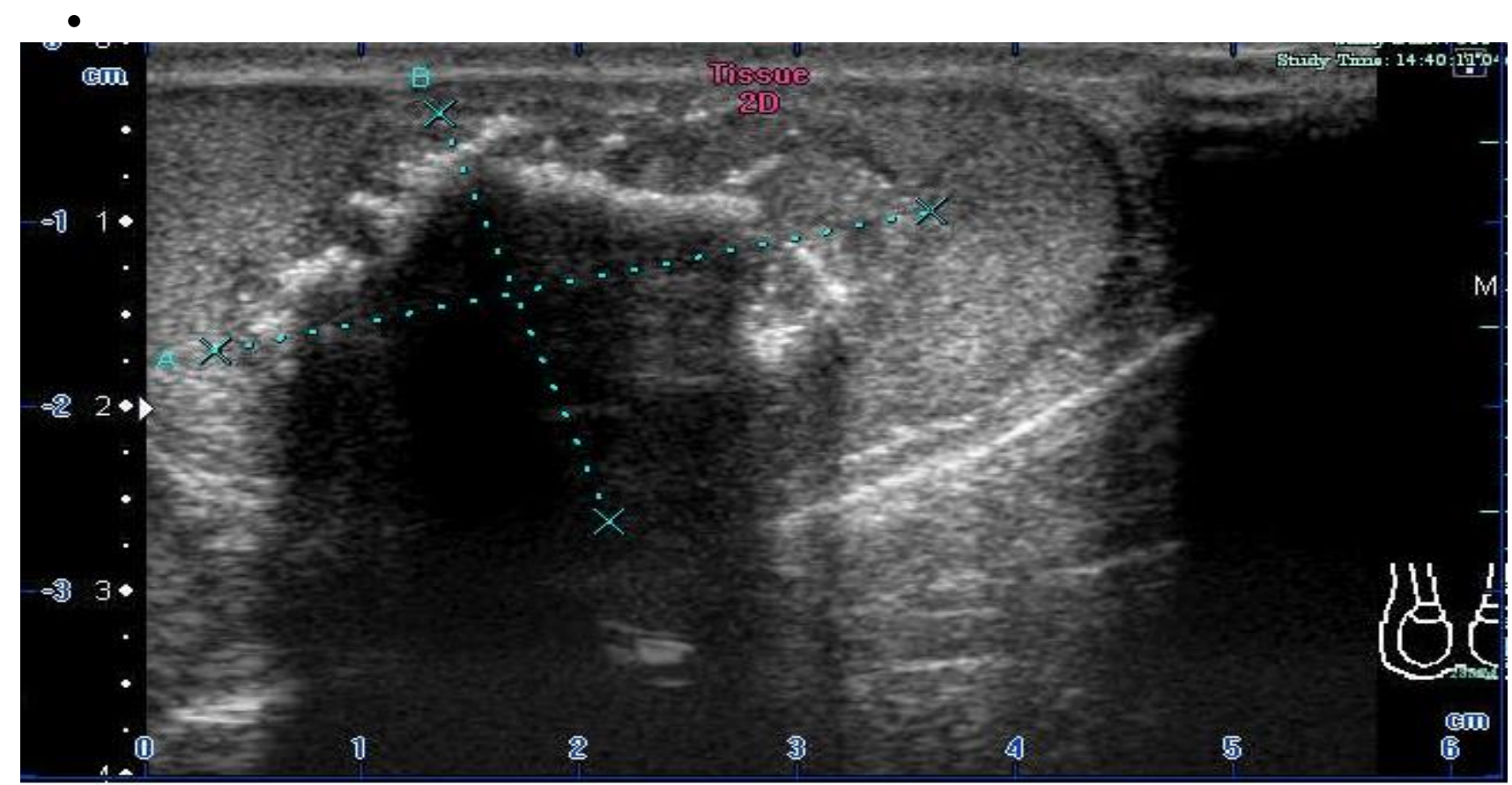

Figure 18: Scrotal ultrasound revealed a roundish, well-demarcated, hypoechoic mass with calcifications in the left testicle. Reproduced from: [23] Liu B, Chen J, Luo J, Zhou F, Wang C, Xie L. Cavernous hemangioma of the testis mimicking a testicular teratoma. Exp Ther Med 2013; 6: 91 - 92. DOI: 10.3892//etm.2013.1086. Copyright (C) 2013, Spandidos Publications This is an open access article licensed under a Creative Commons Attribution- 
NonCommercial 3.0 Unported License. This article may be redistributed, reproduced and reused for noncommercial purposes, provided the original source is properly cited.

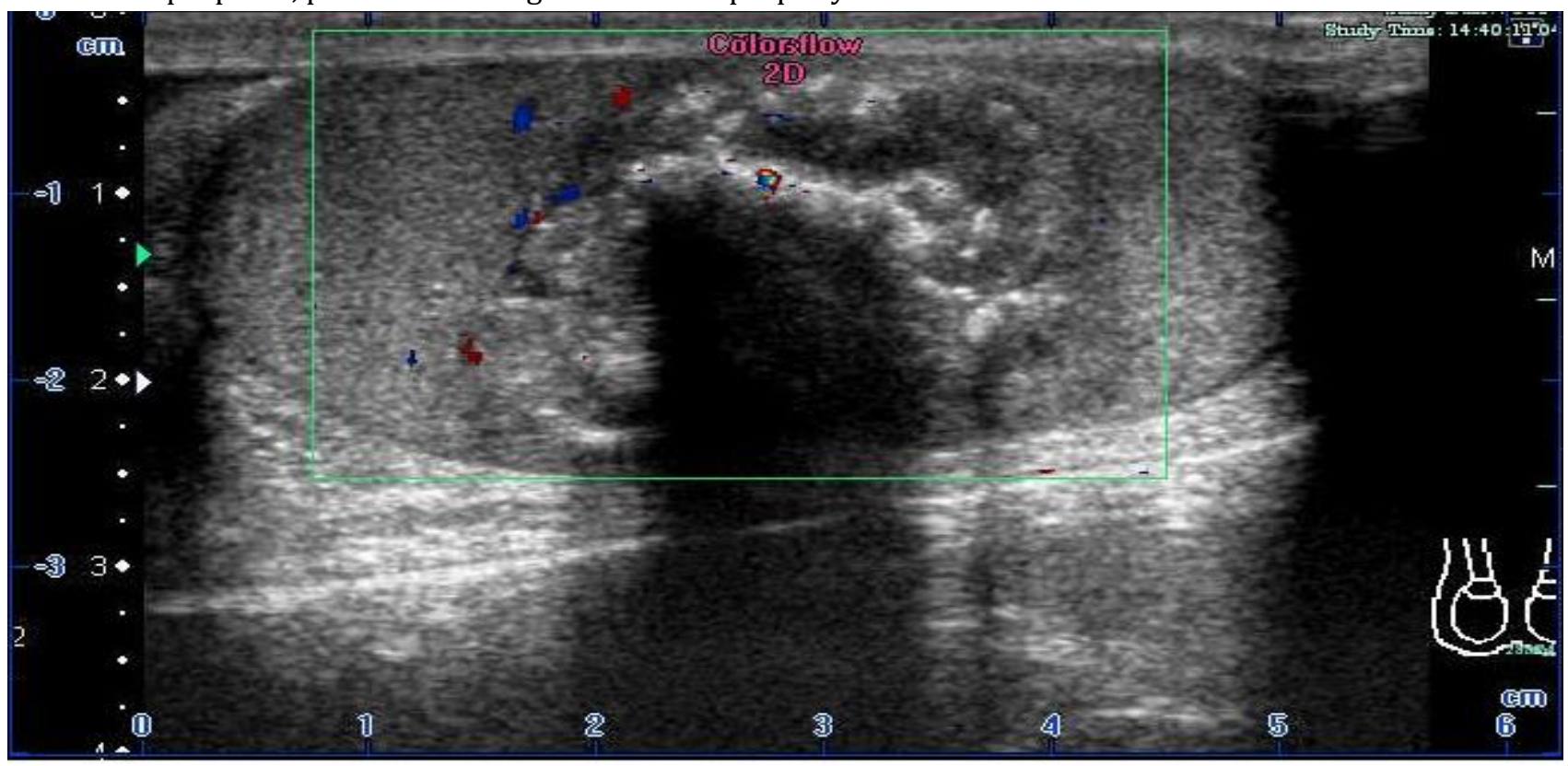

Figure 19: Scrotal ultrasound. The left testicular mass demonstrated blood flow in color Doppler sonography. Reproduced from: [23] Liu B, Chen J, Luo J, Zhou F, Wang C, Xie L. Cavernous hemangioma of the testis mimicking a testicular teratoma. Exp Ther Med 2013; 6: 91 - 92. DOI: 10.3892//etm.2013.1086. Copyright (c) 2013, Spandidos Publications This is an open access article licensed under a Creative Commons Attribution-NonCommercial 3.0 Unported License. This article may be redistributed, reproduced and reused for non-commercial purposes, provided the original source is properly cited.

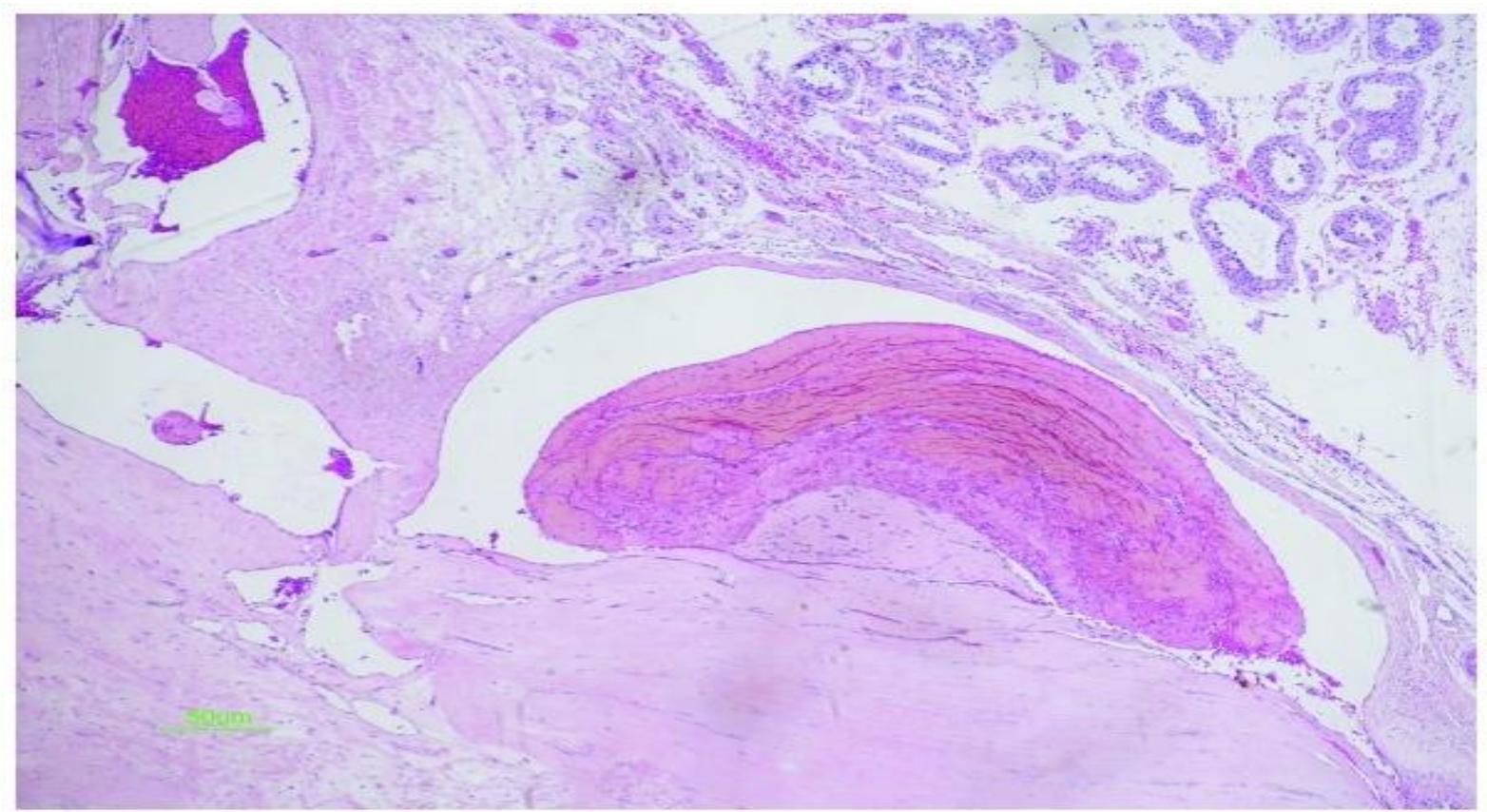

Figure: 20: Photomicrograph of a section of the testis reveals a cavernous hemangioma. Original magnification, $x$ 50. Reproduced from: [23] Liu B, Chen J, Luo J, Zhou F, Wang C, Xie L. Cavernous hemangioma of the testis 
mimicking a testicular teratoma. Exp Ther Med 2013; 6: 91 - 92. DOI: 10.3892//etm.2013.1086. Copyright (C) 2013, Spandidos Publications This is an open access article licensed under a Creative Commons AttributionNonCommercial 3.0 Unported License. This article may be redistributed, reproduced and reused for noncommercial purposes, provided the original source is properly cited.

Wong et al. [20] reported a healthy 66-year-old man who had manifested with a painless palpable left testicular mass. The results of his serum tumour markers including Beta Human Chorionic Gonadotrophin, alpha fetoprotein, and lactate dehydrogenase were within normal range. He had ultrasound scan of his scrotal contents which showed a homogeneous hypoechoic nodule in his left testis that measured $2.8 \mathrm{~cm}$ in size and which upon colour Doppler scanning showed increased vascular flow. A malignant tumour of the testis was suspected hence he underwent an uncomplicated left radical orchidectomy. Macroscopic examination of the specimen showed a well-demarcated tan-brown nodule which had measured $2.8 \mathrm{~cm} \times 2.5 \mathrm{~m} \mathrm{x} \mathrm{2,2} \mathrm{cm}$ within the parenchyma of the testis with no extension into the tunica albuginea. Microscopy pathology examination of the tumour showed groups of capillaries of varying sizes that had been arranged in lobular fashion with spindled-like endothelial cells lining the capillary structures. The circumscribed vascular lesion was noted to be well-demarcated from the parenchyma of the testis by a fibrous $0.1-\mathrm{cm}$ pseudo-capsule. There was lack of any mitotic activity, anaplasia, and dysplasia which did illustrate that the lesion was benign in nature. Immunohistochemistry staining of the tumoral lesion exhibited positive staining for endothelial markers CD31 and CD34 and it did exhibit negative staining for mesothelial markers Calretinin, WT1, and for lymphatic marker D2-40 which had excluded adenomatoid tumour of the testis. Based upon the pathology examination features of the tumour a diagnosis of capillary haemangioma of the testis was made. He was well at his 6-months follow-up without any evidence of recurrence. Wong et al. [20] stated the following

- Out of the 22 cases of haemangioma of the testis that had been reported by the time of their case report, the mean age of the reported patients was $25.1+/-22.7$ years and the ages had ranged between 6 months and 80 years. Majority of the haemangioma of the testis cases had involved children or young adults and $59 \%$ of the patients who were affected were younger than 19 years.

- The presentation did involve report of a testicular mass in $80 \%$ of cases and $15 \%$ of them were associated with pain. One patient was asymptomatic and the lesion was identified incidentally upon ultrasound scanning. [24]

- With regard to the reported cases of haemangioma of the testis, the lesion had involved the left testis in 9 cases, and the right testis in 7 cases but the site of the haemangioma was not documented with regard to 5 cases reported.

- The results of the testicular tumour markers were normal in all cases reported.

- With regard to haemangiomas of the testis ultrasound scanning did show hypo-echoic lesions in $76 \%$ of the cases and hypervascularity in $82 \%$ of the lesions.

- Magnetic resonance imaging was undertaken in 2 cases. Essig et al. [11] did report that T1 postcontrast images did show intense heterogeneous contrast-enhancement, whilst T2 did demonstrate hypo-intensity of the lesion. Zaidi and Fathaddin [12] had reported a welldemarcated lobulated mass that had similar magnetic resonance imaging signal intensity as seminoma tumours. Considering that haemangiomas of the testis tend to be typically poorly defined and they tend not to be distinguishable from malignant tumours, it would prove difficult 
to determine pre-operatively if the lesions are benign or malignant. In view of this $65 \%$ of the reported patients who had haemangioma of the testis had undergone radical orchidectomy and $35 \%$ had undergone a partial orchidectomy pursuant to intra-operative frozen section showing capillary haemangioma of the testis.

- It would be important for both urologists and pathologists to be conversant with the possibility of haemangiomas of the testis as well as other benign adult testicular tumours.

- Even though the rarity of haemangiomas of the testis does preclude significant changes to be made with regard to the way urologists approach adult testicular masses, the possibility of a benign testicular tumour should be borne in mind with a high index of suspicion. This index of suspicion would be pertinent particularly with regards to scenarios when the patient does fall outside the typical age group range for germ cell tumours, as well as for patients who have solitary testis.

- With regard to cases of testicular tumoral mass where the lesion is strongly suspected to be benign and the serum levels of testicular tumour markers are normal, then intra-operative frozen section pathology examinations should be requested. Partial orchidectomy could be undertaken for histopathology examination confirmed benign testicular tumours including capillary haemangioma of the testis.

Bsilat et al. [25] presented a case of a 16-years-old boy with idiopathic delayed puberty who had been treated by testosterone and who had a history of preputial plastic surgery who had been undergoing follow-up assessment. The results of his germ cell tumour markers were normal including serum Beta Human Chorionic Gonadotrophin, alpha fetoprotein, and lactate dehydrogenase. He had ultrasound scan of his scrotal contents which showed an intratesticular nodule that measured $6 \mathrm{~mm} \times 5 \mathrm{~mm} \times 8 \mathrm{~mm}$ and doppler ultrasound scan of the testis had demonstrated lots of vessels. His last serum testosterone levels were normal. He underwent partial orchidectomy to remove the testicular lesion under the guidance of intra-operative ultrasound scan control. Pathology examination of the excised testicular lesion revealed features that were consistent with haemangioma with lots of benign capillary channels and immunohistochemistry studies showed positive staining with CD31. Bsilat et al. [25] also stated that:

- Echography cannot affirm definitely the histology of a testicular tumour but it can lead the clinician to take into consideration the possible benign or malignant nature of a testicular lesion which should enable the surgeon to consider partial orchidectomy with frozen section pathology examination and in cases of haemangioma of the testis, the pathology examination could show 4 types of haemangioma of the testis (cavernous, histiocytoid, capillary, and endothelial hyperplasia.

- Histopathology examination would tend to show vascular tumour with well-differentiated endothelia. The vessels would tend to be large with thin walls and no excessive atypia or mitosis would be seen. 


\section{Conclusions}

- Haemangioma of the testis is an extremely rare benign lesion which has been reported in less than 60 occasions globally and it can affect individuals of all age groups from children to adults but it tends to be more common in individuals who are younger than 20 years of age.

- Haemangiomas of the testis tend to have ultrasonographic and magnetic resonance imaging features that could simulate that of malignant testicular tumours especially seminoma but at times certain features may give the radiologists and urologists the idea of the lesion being benign especially in association with negative serum levels of germ cell tumour markers even though the features themselves would not be diagnostic of Haemangioma of the testis.

- Clinicians, urologists, and pathologists should be aware of this uncommon disease entity of Haemangioma of the testis in view of the fact that the presentation, clinical examination findings, and the results of radiology imaging studies tend not to be sufficient to enable them establish a definitive correct diagnosis of the disease without pathology examination of the testicular lesion. All testicular tumoral lesions that are associated with normal serum germ cell tumour marker levels should be explored by the trans-inguinal route and excised completely for intra-operative frozen section pathology examination and if the results confirm Haemangioma of the testis then testis-preserving operation would be applicable and thus enable the avoidance of unnecessary radical orchidectomy on such patients. Nevertheless if frozen section pathology services are not available especially in some hospitals in the developing countries then radical orchidectomy could be undertaken provided the contralateral testis is normal.

- The association of torsion of the testis with Haemangioma is extremely rare but it has been reported on one occasion.

\section{Acknowledgements}

- $\quad$ Exp Ther Med and Spandidos Publications for granting permission for reproduction of contents and figures and contents of their Journal article under Creative Commons License.

- Radiology Case Reports and Elsevier for granting permission for reproduction of contents and figures from their Journal article under Creative Commons License.

- International Journal of Surgery Case Reports and Elsevier for granting permission for reproduction of figures and contents of their journal article Under a Creative Commons License.

- Journal of Ultrasonography and the Polish Ultrasound Society for granting permission for reproduction of contents and figures from their Journal article under Copyright (C) Polish Ultrasound Society. Published by Medical Communications Sp. z. o. o. All rights reserved. This is an open-access article distributed under the terms of the Creative Commons Attribution-NonCommercialNoDerivatives License (CC BY-NC-ND). Reproduction is permitted for personal, educational, noncommercial use, provided the original article is in whole, unmodified, and properly cited.

- Indian Journal of Pathology \& Microbiology and Wolters Kluwer Medknow for granting permission for reproduction of contents and figures from their Journal article under Open Access Publication and Creative Commons Licensing This is an open access article journal, and articles are distributed under the terms of the Creative Commons Attribution-NonCommercial-ShareAlike 4.0 License, which allows others to remix, tweak, and build upon the work non-commercially, as long as appropriate credit is given and the new creations are licensed under the identical terms. 


\section{References}

1. Bialek W, Rudzki S, Wronecki L. Capillary haemangioma of the testis. A case report of a rare benign tumor. Journal of Ultrasonography. 2016 Mar; 16(64): 87 - 93. DOI: $\quad 10.15557 / J o U .2016 .0009$ https://www.ncbi.nlm.nih.gov/pmc/articles/P MC4834374/

2. Mungan $S$, Turguptalp H, Ersöz S, Keskin F, Kutlu 0. A rare neoplasm of the testis: capillary hemangioma. Turk Patoloji Derg. 2011 Jan; 27(1): $80 \quad-\quad 83$ http://www.turkjpath.org/pdf/pdf TPD 1472. pdf

3. Albers P, Albrecht W, Algaba F, Bokemeyer C, Cohn-Cedermark G, Fizazi K, Horwich A, Laguna M P, Nicolai N, Oldenburg J. Guidelines on Testicular Cancer: 2015 Update. European Urology 2015 Dec; 68(6): 1054 - 1068 DOI: 110.1016/j.eururo.2015.07.044

4. Cochlin D L. The scrotum In: Cochlin D L, Dubbins P A, Goldberg B B, Halpern E J, editors. Urogenital Ultrasound. London-New York: Taylor \& Francis; 2006. 183 - 255.

5. Jacubowski W, Szopiński T, Moszna. In: SudolSzopińska I, Szopiński T. editors. Diagnostyka ultrasonograftii; 2007; 129 - 153.

6. Gordedsky J. Testis and epididymis Other tumors not specific to testis Hemangioma. PathologyOutlines.com. Topic Completed 2013 Sep 01; Revised 2019 Mar 28. http://www.pathologyoutlines.com/topic/test ishemangioma.html

7. Montgomery E, Epstein J I. Anastomosing haemangioma of the genitourinary tract: a lesion mimicking angiosarcoma. Am. J. Surg. Pathol. 2009 Sep; 33(9): 1364 - 1369 DOI: 10.1097/PAS.0b013e3181ad30a7 https://www.ncbi.nlm.nih.gov/pubmed/1960 6014 Accessed 2019 Dec 06

8. Kryvenko 0 N, Epstein J I. Testicular hemangioma. : a series of 8 cases. Am. J. Surg. Pathol 2013 Jun; 37(6): 860 - 866. DOI: 10.1097/PAS.0b013e318278817f. https://www.ncbi.nlm.nih.gov/pubmed/2366 5824 Accessed 2019 Dec 06

9. Carmignani L, Gadda F, Gazzano G, et al. High Incidence of benign testicular neoplasms diagnosed by ultrasound. J. Urol. 2003; 170:
$1783 \quad-\quad 1786 \quad \underline{\text { https://moh- }}$

it.pure.elsevier.com/en/publications/high-

incidence-of-benign-testicular-neoplasms-

diagnosed-by-ultras

10. Ricci Z, Koenigsberg M, Whitney K, Sonography of an arteriovenous-type hemangioma of the testis. AJR Am J Roentgenol 2000 Jun; 174(6); 1581 - 1582 DOI: 10.2214/ajr.174.6.1741581

https://www.ajronline.org/doi/full/10.2214/ ajr.174.6.1741581

11. Essig M, Knopp M V, Hawighorst $H$, van Kaick G. MRI of capillary hemangioma of the testis. J Comput Assist Tomogr 1997 May-Jun; 21(3): 402-404 DOI: $10.1097 / 00004728-$ 199705000-00012

http://europepmc.org/article/MED/9135648

12. Zaidi S N, Fathaddin A A. Testicular capillary hemangioma - a case report of a rare tumor. Indian J Pathol Microbiol 2012 Oct-Dec; 55(4): 557 - 579 DOI: 10.4103/0377-4929.107815 www.ijpmonline.org/article.asp?issn=03774929; year $=2012 ;$ volume $=55 ;$ issue $=4 ;$ spage $=5$ 57; epage $=559$; aulast $=$ Zaidi

13. Passman $C$, Urban $D$, Klemm $K$, Lockhart $M$, Kenney P, Kolettis P. Testicular lesions other than germ cell tumours: feasibility of testissparing surgery. BJU Int. 2009 Feb; 103(4): $488 \quad-\quad 491$. DOI: $10.1111 / \mathrm{j} .1464-$ 410X.2008.07986.x.

https://www.ncbi.nlm.nih.gov/pubmed/1879 3303 Accessed 2019 Dec 06

14. Suriawinata A, Talerman A, Vapnek J M, Unger P. Hemangioma of the testis: Report of unusual occurrences of cavernous hemangioma in a fetus and capillary hemangioma in an older man. Ann Diagn Pathol 2001 Apr; 5(2): 80 - 83 DOI: $\quad$ 10.1053/adpa.2001.23022 https://www.ncbi.nlm.nih.gov/pubmed/1129 4992?dopt=Abstract

15. Stille J R, Nasrallah P F, McMahon D R. Testicular capillary hemangioma: An unusual diagnosis suggested by duplex color flow ultrasound findings. J Urol. 1997 Apr; 157(4): 1458 - 1459 DOI: 10.1016/s00225347(01)65022-5

https://www.ncbi.nlm.nih.gov/pubmed/9120 981?dopt=Abstract

16. Takaoka E, Yamaguchi $\mathrm{K}$, Tominaga $\mathrm{T}$. Cavernous hemangioma of the testis. A case 
report and review of the literature. Hinyokika Kiyo 2007 Jun; 53(6): 405 - 407. https://www.ncbi.nlm.nih.gov/pubmed/1762 8940?dopt=Abstract

17. Mazal $P$ R, Kratzik C, Kain R, Susani M. Capillary haemangioma of the testis. J Clin Pathol. 2000 Aug; 53(8): 641 - 642 DOI: $10.1136 /$ jcp.53.8.641 https://www.ncbi.nlm.nih.gov/pubmed/1100 2773?dopt=Abstract

18. Banks E R, Mills. S E. Histiocytoid (epithelioid) hemangioma of the testis. The so-called vascular variant of "adenomatoid tumor" Am Surg Pathol. 1990 Jun; 14(6): 584 - 589 DOI:10.1097/00000478-199006000-00010 https://www.ncbi.nlm.nih.gov/pubmed/2186 $\underline{645}$

19. Venkatanarasimha N, McCormick F, Freeman $S$ J. Cavernous Hemangioma of the Testis. Journal of Ultrasound in Medicine. 2010 May; 29(5): $\quad 859 \quad-\quad 860$. https://doi.org/10.7863/jum.2010.29.5.859 https://onlinelibrary.wiley.com/doi/full/10.7 863/jum.2010.29.5.859?sid=nlm\%3Apubmed

20. Wong N C, Dason S, Pozdnyakov S, Alexopoulou I, Greenspan M. Capillary haemangioma of the testis: a rare benign tumour. Can Urol. Assoc J. 2015 Mar-Apr; 9(34): 133 - 135. DOI: 10.5489/cuaj.2318 https://www.ncbi.nlm.nih.gov/pubmed/2608 5871

21. Tepeneu F, Krafka K, Meglic S, Rogatsch H, fsching G. Testicular cavernous hemangioma associated with testicular torsion - case report and review of the literature. International
Journal of Surgery Case Reports. 2018; 49: 247

- 250.

https://doi.org/10.1016/i.ijscr.2018.06.019

//www.sciencedirect.com

22. Abda R B, Bess D, Nieves-robbins N. testicular hemangioma mimicking a malignant neoplasm. Radiology Case Reports 2016 Jun; 11(2): $121 \quad-\quad 123 . \quad$ DOI: 10.1016/j.radcr.2015.12.005

https://www.ncbi.nlm.nih.gov/pmc/articles/P MC4878950/

23. Liu B, Chen J, Luo J, Zhou F, Wang C, Xie L. Cavernous hemangioma of the testis mimicking a testicular teratoma. Exp Ther Med 2013 Jul; 6(1): 91 - 92. DOI: 10.3892//etm.2013.1086

https://www.ncbi.nlm.nih.gov/pmc/articles/P MC3735630/

24. Sheu G L, Hammer Y, Kirsch A. Testicular capillary hemangioma presenting as an incidental contralateral lesion in a child with cryptorchidism. Urology 2012 Nov; 80(5): 1135 - $1137 . \quad$ DOI: 10.1016/j.urology.2012.07.026

https://www.sciencedirect.com/science/articl e/pii/S0090429512008084

25. Bsilat M, Jorion J L, Rahier O, Puttemans T, Dardenne E. Hemangioma: rare testicular tumor. Clinique Saint Pierre Ottignies Presented at the $18^{\text {th }}$ Annual Congress Belgian Association of Urology 2018 Dec 6 \& 7; https://bau2018.com/wpcontent/uploads/2018/12/16-BAU-2018Bsilat-Mehdi.pdf

How to cite this Article: * Anthony Kodzo-Grey Venyo; Haemangioma of the Testis: A Review and Update of the Literature

Int. Res. Med. Health Sci., 2019; (2-6): 12-43

Source of Support: Nil, Conflict of Interest: None declared.

Received: 08-12-2019; Revision: 24-12-2019; Accepted: 25-12-2019 